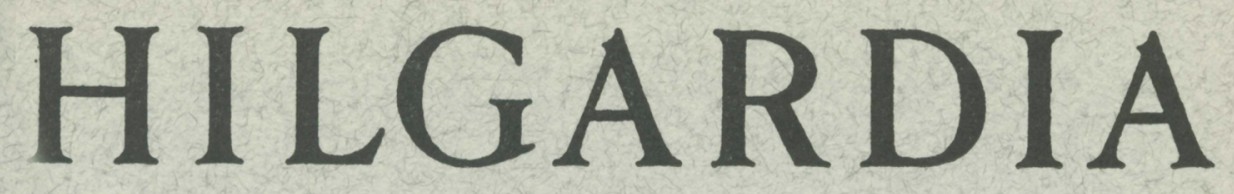

A Journal of Agricultural Science Published by the California Agricultural Experiment Station

\title{
THE EFFECT OF DEVELOPMENTAL STAGE ON DIRECTION OF TRANSLOCATION OF PHOTOSYNTHATE IN VITIS VINIFERA
}

\author{
CHARLES R. HALE \\ and \\ ROBERT J. WEAVER
}

UNIVERSITY OF CALIFORNIA • BERKELEY, CALIFORNIA 
The direction of translocation of $\mathrm{C}^{14}$ following the assimilation of $\mathrm{C}^{14} \mathrm{O}_{2}$ by single leaves or shoot tips of the Muscat of Alexandria grapevine was determined by using radioautographic techniques. The first assimilate exported by the treated leaf was to the shoot tip. When the treated leaf was separated from the oldest importing leaf on the shoot tip by two or three other exporting leaves, the assimilate from the leaf was translocated both to the shoot tip and to the parent vine. With further shoot growth the basipetal movement predominated until translocation from a treated leaf below the shoot tip was completely reversed and was basipetal only. Translocation from leaves below the cluster was partially reversed again when fruit development started. Assimilate from these leaves was translocated both to the fruit cluster and parent vine. After the rate of shoot elongation decreased sharply, radiocarbon moved from the shoot tip in a basipetal direction.

The young inflorescence had small power as a sink compared to the shoot tip and the parent vine, and was unable to influence the direction of translocation. From 10 to 14 days before bioom until fruit set the cluster was a weak sink.

Axillary buds, tendrils, xylem, parenchyma, and pith were found normally to be weak sinks relative to the developing fruit cluster and unable to influence the longitudinal direction of translocation.

Axillary shoots behaved as young leaves until 1 or 2 of their leaves were mature. Then no assimilate moved into them from the main shoot.

Shoot tips and parent vines were more powerful sinks than the cluster during flower development but not during fruit set. Girdling and topping thus affect fruit set because they divert more assimilates into the cluster just prior to fruit set. 


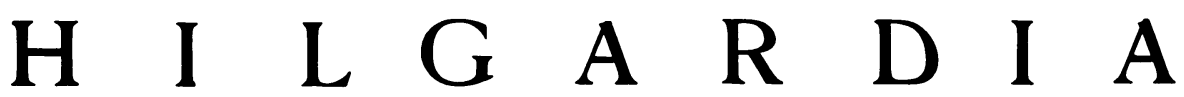

A Journal of Agricultural Science Published by

the California Agricultural Experiment Station

\begin{tabular}{lcr}
\hline Vol. 33 & OстовеR, 1962 & No. 3 \\
\hline THE EFFECT OF DEVELOPMENTAL STAGE ON DIRECTION OF \\
TRANSLOCATION OF PHOTOSYNTHATE IN \\
VITIS VINIFERA
\end{tabular}

\section{CHARLES R. HALE and ROBERT J. WEAVER}

Most of our present knowledge of the movement of carbohydrates in the grapevine is based upon analyses of parts of the vine at different developmental stages (Winkler and Williams, 1945). Such correlative studies are of great value in understanding the general changes in the food reserves in various parts of the vine during the season. However, such work does not tell whether the translocate from leaves moves in only one direction or in two directions at once, or when changes in direction take place.

Although much is known about the principles of translocation and the factors affecting the direction of transport, there is little specific information about the translocation patterns during the ontogeny of the grapevine shoot. Experiments were therefore initiated with radioisotopes to examine translocation patterns. These were designed to determine when the leaves start exporting carbohydrate, when the shoots start supplying carbohydrate to the parent vine, and the effects of various sinks such as the shoot tip, inflorescence, and fruit cluster on the direction of translocation.

This work should contribute to our understanding of the carbohydrate economy of the vine. The results may also apply to some extent to problems of flower development and fruit set, foliage application of growth regulators, foliage application of mineral nutrients, and the use of systemic fungicides and insecticides.

\section{REVIEW OF LITERATURE}

Translocation of organic and inorganic solutes in plants has been reviewed extensively during the past two years (Swanson, 1959; Biddulph, 1959; Zimmerman, 1960; Crafts, 1961; and Kursanov, 1961). Physiology of the phloem has been reviewed by Esau, Currier, and Cheadle (1957).

There are few experimental data on the movement of assimilates in the grapevine. Defoliation and girdling experiments have shown that synthesized materials move freely to any fruit cluster on the vine regardless of

${ }^{1}$ Submitted for publication January 25, 1962.

2 The data presented here are taken from a portion of the Ph.D. thesis of Charles $R$. Hale, presented to the Graduate Division, University of California, Davis, January 3, 1962.

${ }^{3}$ Research Assistant in the Department of Viticulture and Enology, Davis.

${ }^{4}$ Professor of Viticulture, and Viticulturist in the Experiment Station, Davis. 
position (Winkler, 1932; Negrul' and Nikiforova, 1958). Investigations on the relation between girdling and the carbohydrate nutrition of developing fruit have shown that girdling increases the level of carbohydrates above the girdle (Weaver and McCune 1959b; Coombe, 1959). This is in agreement with the general experience that girdling prevents the downward movement of assimilates. Coombe (1959) found that more $\mathrm{C}^{14}$ was recovered from the shoot tip than from the flowers when labeled sucrose was applied to the leaf opposite the cluster on a girdled shoot at full bloom. Sixteen leaves on a girdled Muscat shoot produced fruit with a higher sugar content than did 27 leaves on an ungirdled shoot (Winkler, 1930). This difference is probably a reflection of the competition between the developing fruit and other organs, especially the roots, for the photosynthetic products.

Winkler and Williams (1945) followed the changes in the carbohydrates in different parts of the Carignane vine for one annual growth cycle. They found that early shoot growth utilized bark reserves primarily, while it depleted relatively small localized areas of the inner trunk reserves. Although the bark reserves of the trunk reached a minimum in mid-June, those in the roots, where the carbohydrate level was high, continued to be utilized until late July, 5 or 6 weeks later.

Stoev, Mamarov, and Benchev (1960) concluded from a study of the sap exuded from the ends of cut roots and shoots that glucose played an important role in the movement of carbohydrates from the roots to the aerial parts of the vine. They found that this movement of nutrients in the sap ceased at flowering time. Such exudation was undoubtedly from the xylem and hence the observed transport.

The deleterious effects of increased pruning severity on flower formation and fruit set were correlated with decreased levels of carbohydrate, particularly sugars, in the shoots and the flowers (Winkler, 1929).

Translocation of 4-CPA (4-chlorophenoxyacetic acid) and gibberellins in several varieties of grape was investigated by Weaver and McCune (1957; $1959 a ; 1959 c)$. The extent of translocation was measured by the growth response shown by the shoot tips or the inflorescence, or by the effect of the substances on fruit set or development. Leonard and Weaver (1961) investigated the absorption of $\mathrm{C}^{14}$-labeled 2,4-D and Amitrole in the Tokay grapevine. They found that translocation from leaves just below and above the cluster was mainly acropetal, but when the shoots were about 3 to 4 feet long translocation became basipetal. Flower clusters were weak sinks compared to the shoot tip.

Swanson and El Shishiny (1958) using $\mathrm{C}^{14} \mathrm{O}_{2}$ found that the sucrose was the transport form of sugar in Vitis labrusca L. 'Concord.' Labeled carbon was found in both glucose and fructose along the stem in equal proportions, and the authors considered that these labeled sugars were formed by the hydrolysis of sucrose after it had left the translocational channels.

\section{MATERIALS AND METHODS}

Mature, head-trained, spur-pruned vines of Vitis vinifera L. 'Muscat of Alexandria,' hereafter referred to as Muscat, in an irrigated vineyard at the 
University of California, Davis, were used. The ten-year-old vines were on their own roots, in rows 12 feet apart, and were 6 feet apart within each row. Except for treatment with radioactive carbon dioxide and a certain amount of thinning, all vine treatment was routine.

Translocation patterns of photosynthate within the shoot were followed in 1960 and 1961 by exposing certain leaves to $\mathrm{C}^{14}$-labeled carbon dioxide and by subsequently making radioautographs of the shoots. In 1959, experiments with $\mathrm{C}^{14}$ were made using $\mathrm{C}^{14}$-labeled glucose and fructose as well as carbon dioxide. Absorption of glucose and fructose by mature leaves was poor, and only faint radioautographs were obtained. Therefore glucose and fructose were no longer used.

Uniform shoots which were on the southeast side of the vine and exposed to the sun during the morning hours were used. The selected leaves were exposed to the labeled carbon dioxide for 30 minutes in the period between 8 a.m. and noon. From one to three shoots were treated on the same vine on the same day, but in all cases only one shoot on a given spur was used. Vines on which shoots had been exposed to $\mathrm{C}^{14} \mathrm{O}_{2}$ on some previous occasion were not used again.

Treatment with $\mathbf{C}^{14} \mathrm{O}_{2}$. Treatment of leaves with $\mathrm{C}^{14} \mathrm{O}_{2}$ was performed in the following manner. First, a hole was made in a Number 8 cork with a cork borer, and a wedge-shaped portion, centered on the hole, was cut out with a sharp razor blade. Pieces of foam rubber were glued to the edges of the hole to prevent injury to the petiole. Corks with holes of various diameters were prepared so that a snug fit could be made around petioles of different sizes. When the cork was fitted around the petiole, the wedge-shaped piece was pressed into place and held in position with masking tape. In this manner a good seal was made and the foam rubber prevented damage to the tissues, particularly the conducting tissues, of the petiole.

After the cork was placed around the petiole, a Number 6 polyethylene bag was put around the leaf and the open end was tied firmly around the cork (fig. 1). Two pieces of glass tubing about 2 inches long were passed through holes made in the cork and the polyethylene bag was then connected by Tygon tubing to the vessel used for generating carbon dioxide. A hand aspirator was connected into one of these lines. The carbon dioxide generator consisted of a glass vial fitted with a rubber stopper through which passed two pieces of glass tubing and a dropping funnel.

Carbon-14-labeled barium carbonate having a specific activity of 0.061 $\mathrm{mc} / \mathrm{mg}$ was used as the radioactive source. Preliminary experiments in 1959 showed that $1 \mathrm{mg}$ of the labeled carbonate gave a good radioautograph using the following technique. The barium carbonate was placed in the vial, and five or six drops of 70 per cent lactic acid were run into the vial from the dropping funnel. The lactic acid reacted with the barium carbonate to produce $\mathrm{C}^{14} \mathrm{O}_{2}$. When all the barium carbonate was dissolved, usually after 3 or 4 minutes, the system was aspirated by squeezing the rubber aspirator 15 to 20 times. The aspiration was repeated four or five times during the course of the treatment to ensure proper and complete mixing of the $\mathrm{C}^{14} \mathrm{O}_{2}$ with the atmosphere about the leaf. The bag was removed from around the leaf after an exposure of 30 minutes to the $\mathrm{C}^{14} \mathrm{O}_{2}$. 
Shoot harvest and radioautography. Shoots were harvested 6 or 24 hours after the leaf had been exposed to the labeled carbon dioxide. The treated leaf was first removed from the shoot with a razor blade. The shoot was then cut from the vine and immediately divided into sections with pruning shears to limit any postharvest movement of the radiocarbon. The shoots were

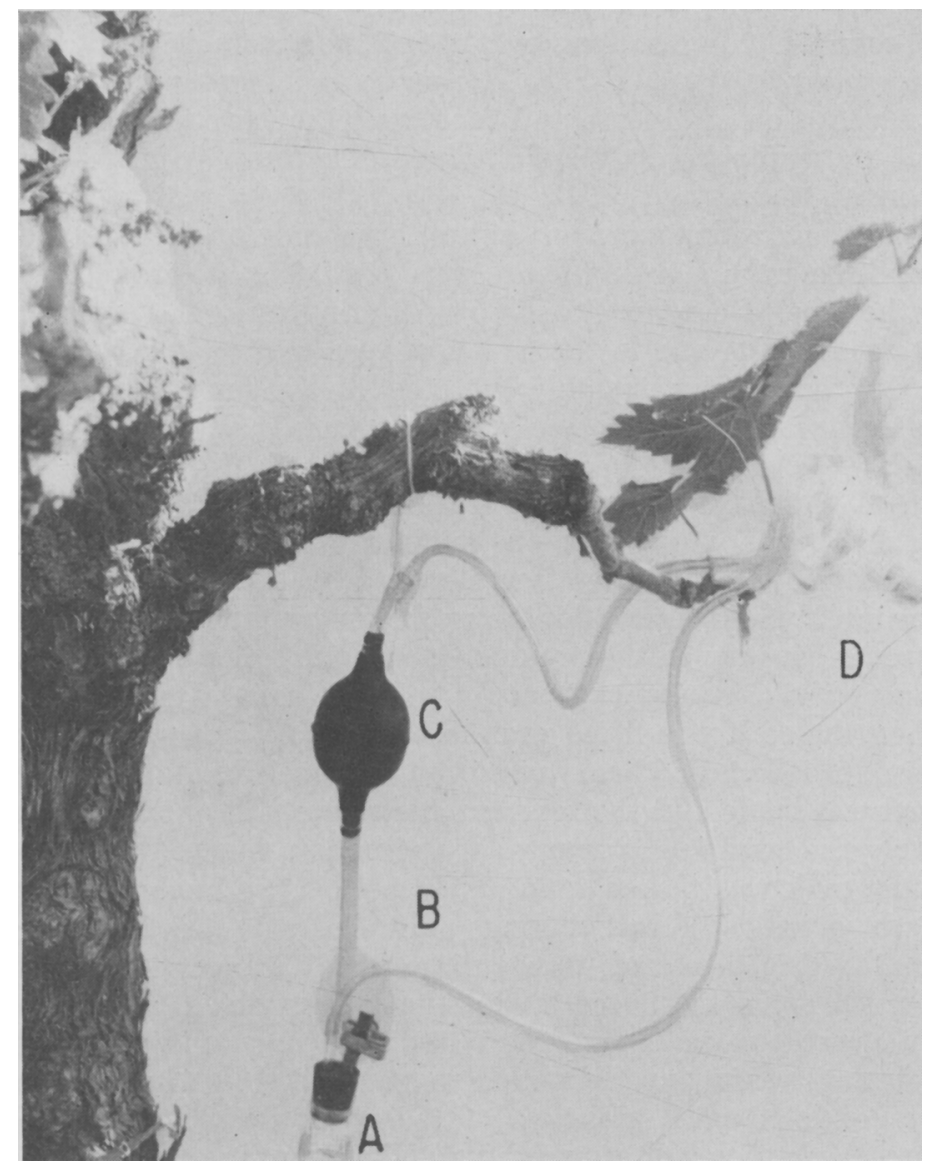

Fig. 1. Portion of a Muscat of Alexandria grapevine showing apparatus for treating a grape leaf with $\mathrm{C}^{14} \mathrm{O}_{2}$. A. Vial containing $\mathrm{BaC}^{14} \mathrm{O}_{3}$. B. Dropping funnel containing lactic acid. C. Aspirator. D. Polyethylene bag fitted around leaf. Photographed in May, 1960.

severed about $1 / 4$ inch above the node bearing the treated leaf, at the node above the treated leaf, at the node below the treated leaf, at the node bearing the inflorescence or fruit cluster, and below the shoot tip (apical 10 to 15 $\mathrm{cm}$ of the shoot). Shoots were additionally severed whenever segments of stem longer than two or three internodes remained after making the five cuts listed above. The severed shoots were then placed in polyethylene bags, taken immediately to the laboratory and held in a refrigerator at $4^{\circ} \mathrm{C}$ usually for 1 to 5 hours, and then prepared for radioautography. 
In most cases the large size of the shoots made it impossible to mount the entire shoot for radioautography. Only representative parts were normally taken:

(1) A cross section from near the middle of each internode,

(2) a longitudinal section of each axillary bud,

(3) a rectangular portion about $2 \mathrm{~cm}$ square of the base of each leaf blade and the distal $1 \mathrm{~cm}$ of the petiole,

(4) branches or berries from the basal, middle, and apical portions of the inflorescence or fruit cluster,

(5) portions of the tendrils, and

(6) approximately the apical $10 \mathrm{~cm}$ of the shoot tip.

Sections were made with a razor blade or sharp knife, and fixed to sheets of $10 \times 12$-inch white paper with a casein glue. The bilateral phyllotaxic arrangement of the grape shoot was preserved when the plant parts were mounted. However, cross sections of shoots were not accurately oriented unless stated so in the text. An example of the arrangement of the parts when mounted is shown in figure 2 . When sections of berries were mounted they were blotted thoroughly to remove free juice before they were fixed to the paper. When the sugar content of the fruit reached about 20 degrees Balling, berry sections often stuck to the X-ray film. Therefore sections of the cluster framework were mounted instead of the berries when the sugar content reached this level (see fig. 11).

The mounted sections were dried in a forced draught oven at $50^{\circ} \mathrm{C}$ for 24 hours. When dry, they were humidified in a closed container over water for about 2 hours and then pressed after the method of Yamaguchi and Crafts (1958). After removal from the press, the mounts were dried at room temperature for 2 to 3 days. Radioautographs were then made by placing the mounts on Kodak Royal Blue X-ray film. The film was exposed for 1 week and then developed so that the distribution of the $\mathrm{C}^{14}$ could be ascertained. Leonard and Weaver (1961) found that pseudo-radioautographs developed if the film was in contact with grape tissue for 4 weeks. In this study no pseudo-radioautographs were produced after a 1-week exposure.

\section{EXPERIMENTATION AND RESULTS \\ Translocation Patterns During Shoot Development in 1960}

Leaves on shoots were treated on each of four different dates in 1960 , to study the translocation pattern of photosynthate at various physiological stages of growth. Treatments were made at prebloom, berry set, veraison (beginning of ripening-deep green color of berry disappears), and harvest. At each stage, leaves in the basal, middle, and apical portions of the shoot were exposed to $\mathrm{C}^{14} \mathrm{O}_{2}$. In some cases the entire apical portion of the shoot was used for the apical treatment.

The treated shoots were harvested 6 hours after exposure to the labeled carbon dioxide in experiments 1 and 2 , and in experiments 3 and 4 the shoots 
[Vol. 33, No. 3

were harvested both 6 and 24 hours after treatment. Each experiment was replicated twice, but since duplicate shoots generally gave similar results, only one replicate shoot is usually presented in this paper. In the experiments where similarity between duplicates was not close, the differences are described in the text.

Experiment 1 (prebloom stage). Treatments were made between May 5 and 7 , about 2 weeks before flowering started. The rapidly growing shoots were about 25 to $30 \mathrm{~cm}$ long, and had nine to twelve leaves.

Either leaf number 2 or 3 was used for the basal treatment, either leaf

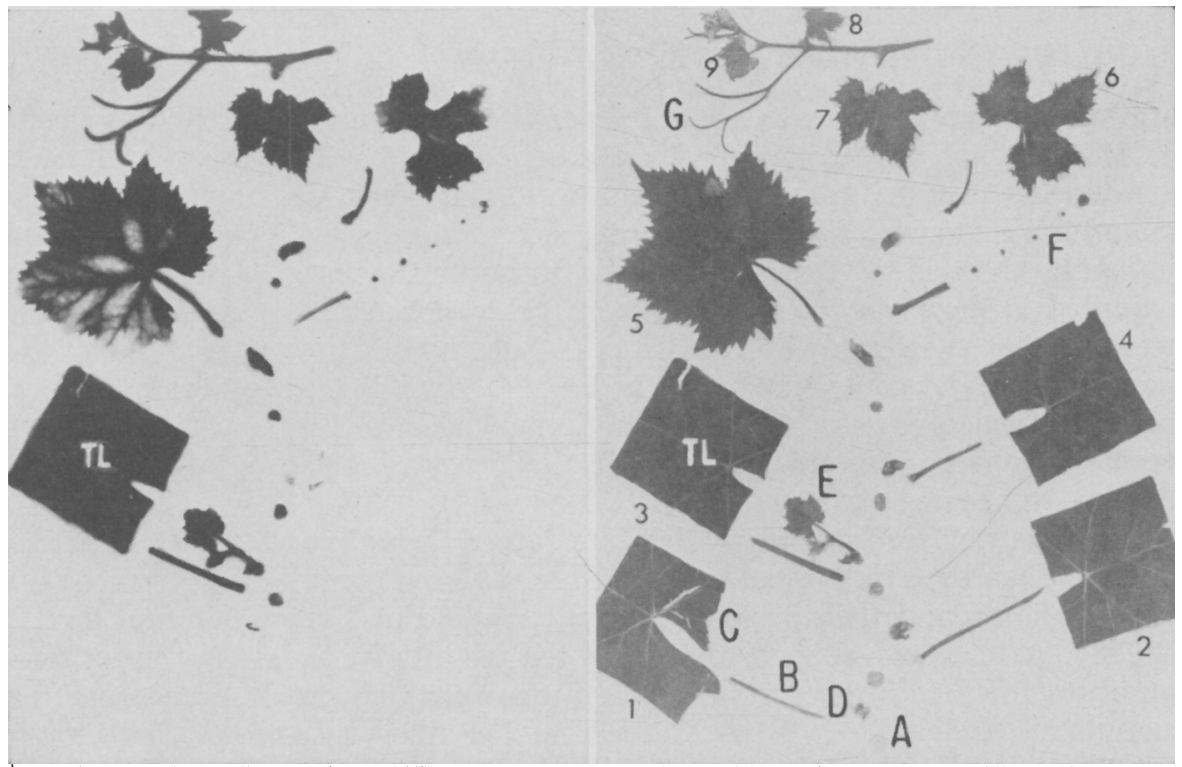

Fig. 2. Ieaf number 3 treated May 5, 1960, about 2 weeks before flowering. Shoot harvested 6 hours after treatment. Left, radioautograph; right, mounted specimens. A. Section of internode. B. Petiole. C. Leaf. D. Axillary bud. E. Axillary shoot. F. Inflorescence. G. Tendril. TL. Treated leaf. The presence of $\mathrm{C}^{14}$ is shown by the dark areas on the radioautograph, the darker the area the higher the concentration of $\mathrm{C}^{14}$. Translocation from the treated leaf was mainly upwards into the shoot tip. The downward movement was restricted to the internode below the treated leaf. Note that the heaviest concentration of $\mathrm{C}^{14}$ is on the same side of the shoot as the treated leaf.

number 4 or 5 for the middle, and the entire terminal $10 \mathrm{~cm}$ of the shoot for the apical treatment. In this paper all leaves are numbered beginning with the basal leaf designated as number one.

The movement of radioactivity from either leaf number 2 or 3 was mainly acropetal (fig. 2). Radioactivity appeared in the bark, xylem, parenchyma, and pith of the stem sections, the axillary buds and shoots, the inflorescence, and the young leaves and tendrils at the shoot apex. More activity appeared in the organs and tissues on the same side of the stem as the treated leaf than on the opposite side. For example when leaf number 2 was treated, much more photosynthate moved into the sixth leaf which was on the same side of 
the stem as the treated leaf, than into the younger seventh leaf which was on the opposite side. Also, much activity was detected in all the axillary buds on the same side of the shoot as the treated leaf, but very little was detected in the buds on the opposite side.

The degree of basipetal movement differed in the two replicate shoots. When leaf number 2 was treated, activity was detected in the second internode below the treated leaf, but when leaf number 3 was treated (fig. 2), photosynthate did not move farther than the first internode below the treated leaf.

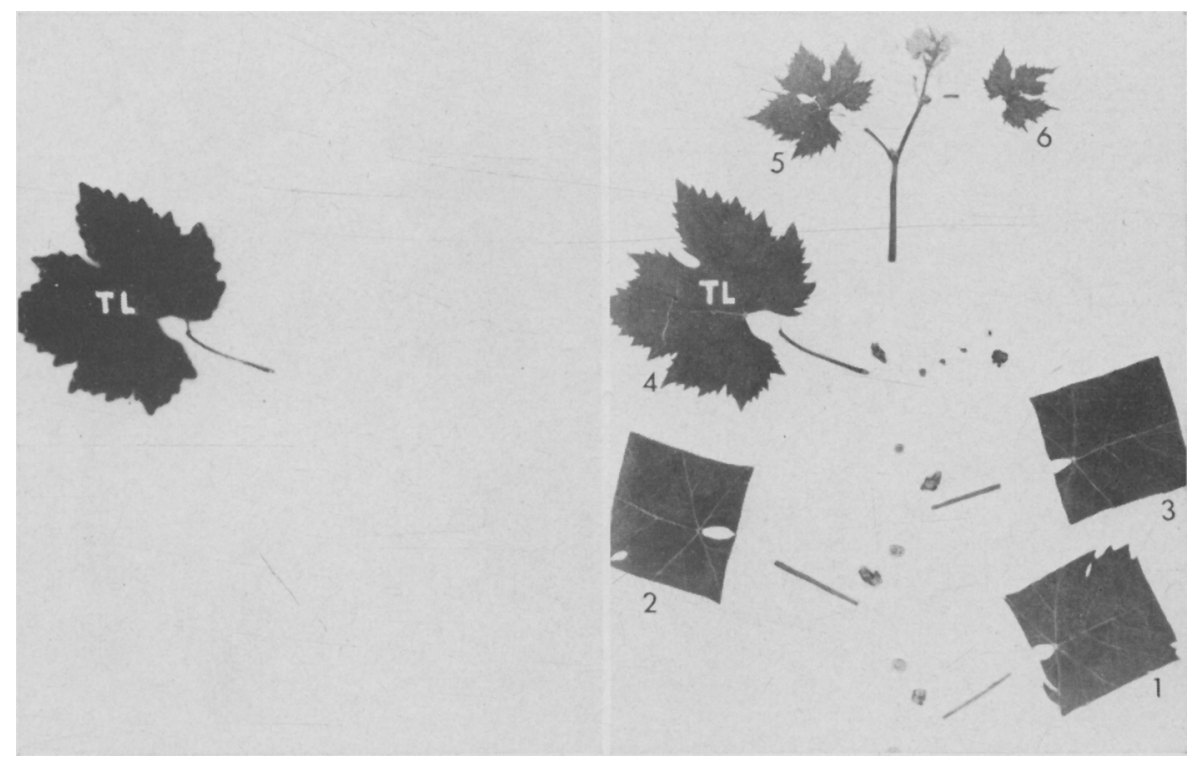

Fig. 3. Leaf number 4 treated May 5, 1960. Shoot harvested 6 hours after treatment. Left, radioautograph ; right, mounted specimens. TL. Treated leaf. There was no translocation out of the treated leaf which was still growing rapidly at time of treatment.

No photosynthate was translocated into the basal four leaf blades of either shoot. In both shoots, however, slight activity could be discerned in the petiole of leaf number 4 . The fifth leaf blade was the youngest to receive activity exported from the older treated leaves.

For treatment of the midportion of the shoot, either leaf number 4 or 5 was used. These pale-green, shiny, thin leaves were about one third of their final size. No photosynthate moved out of these leaves (fig. 3).

For treatment of the apical portion of the shoot, the terminal 5 to $7 \mathrm{~cm}$ of the shoot were exposed to $\mathrm{C}^{14} \mathrm{O}_{2}$. The largest leaf was $2.5 \mathrm{~cm}$ long and 4 $\mathrm{cm}$ wide. No radiocarbon appeared in the stem sections below the treated portion of the shoot (fig. 4). Some radiocarbon appeared in the leaf immediately basal to the treated portion of the shoot. However, the activity in this leaf was restricted to the interveinal region of the lamina. Because of the absence of radiocarbon in the veins and petiole it is unlikely that it was translocated into this leaf from the treated leaves in the usual manner. The 
radiocarbon probably reached the leaf in the gaseous form, either as leakage from the polyethylene bag during treatment, or as carbon dioxide respired by the treated leaves after harvest when the shoot was stored in the polyethylene bag before it was prepared for radioautography.

The latter possibility was investigated by holding an untreated shoot and a treated shoot in a polyethylene bag for several hours and making a radioautograph of the untreated shoot. The result showed that $\mathrm{C}^{14}$ was distributed uniformly over the entire untreated shoot; there was no concentration of activity in any one part of the shoot. Thus, it seems that in radioautographs

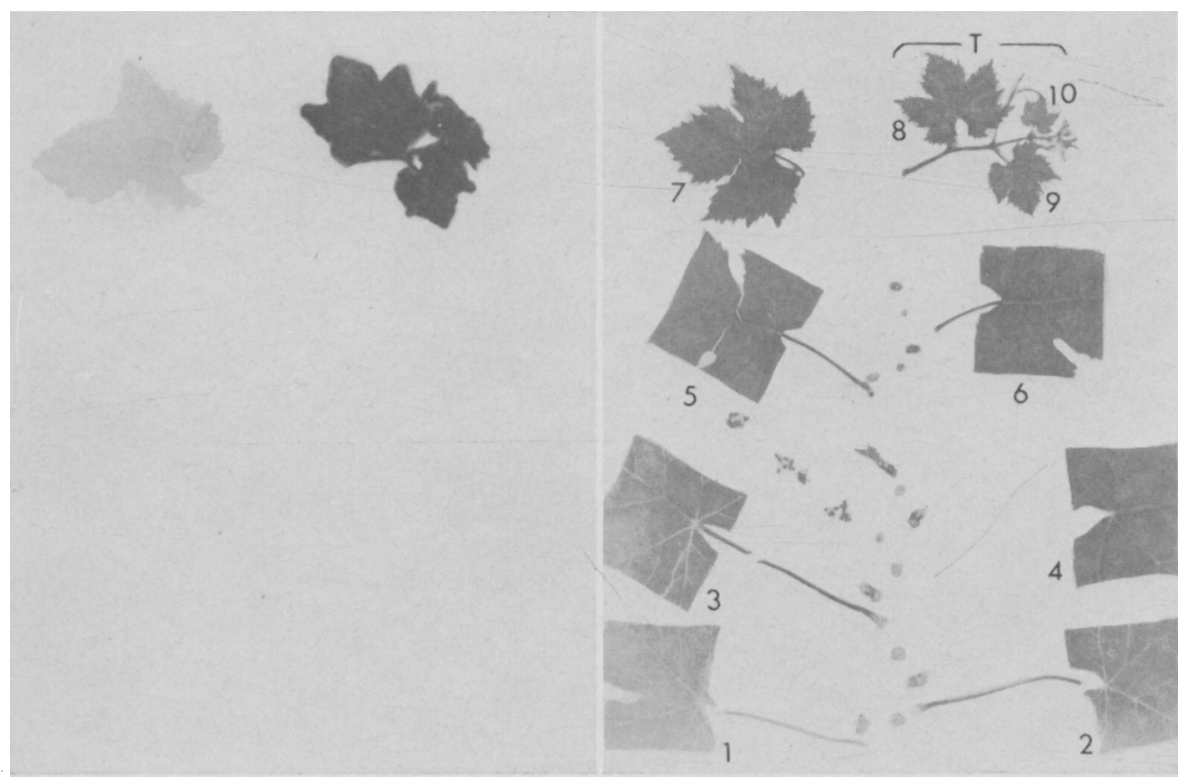

Fig. 4. The terminal portion of the shoot tip treated on May 7, 1960. Shoot harvested 6 hours after treatment. Left, radioautograph; right, mounted specimens. T. Treated shoot. Since the slight activity in the leaf below the treated portion was confined to the lamina and none was present in the veins, it is probable the $\mathrm{C}^{14} \mathrm{O}_{2}$ reached this leaf in a gaseous form.

where activity is faint and uniformly distributed in the leaf, as for example in leaf number 7 of figure 4 , the $\mathrm{C}^{14}$ was distributed in the gaseous form, probably as $\mathrm{CO}_{2}$.

Experiment 2 (berry set stage). In this experiment, leaves were treated between June 7 and 10, 1960, about 2 weeks after completion of flowering. The fruit had set, and the shoots were 70 to $80 \mathrm{~cm}$ long with 18 to 20 leaves.

For the basal treatment, either leaf number 2 or 3 was exposed to $\mathrm{C}^{14} \mathrm{O}_{2}$. Translocation from leaf number 2 was both acropetal into the cluster and basipetal (fig. 5). The slight activity in almost every part of the shoot was probably due to movement of $\mathrm{C}^{14} \mathrm{O}_{2}$ in gaseous form. The activity in the fruit was intense, and it also appeared in the bark and pith of the internode above the treated leaf as well as in the two internodes below it. The activity in the basal internode was less than that in the internode above the treated leaf. 


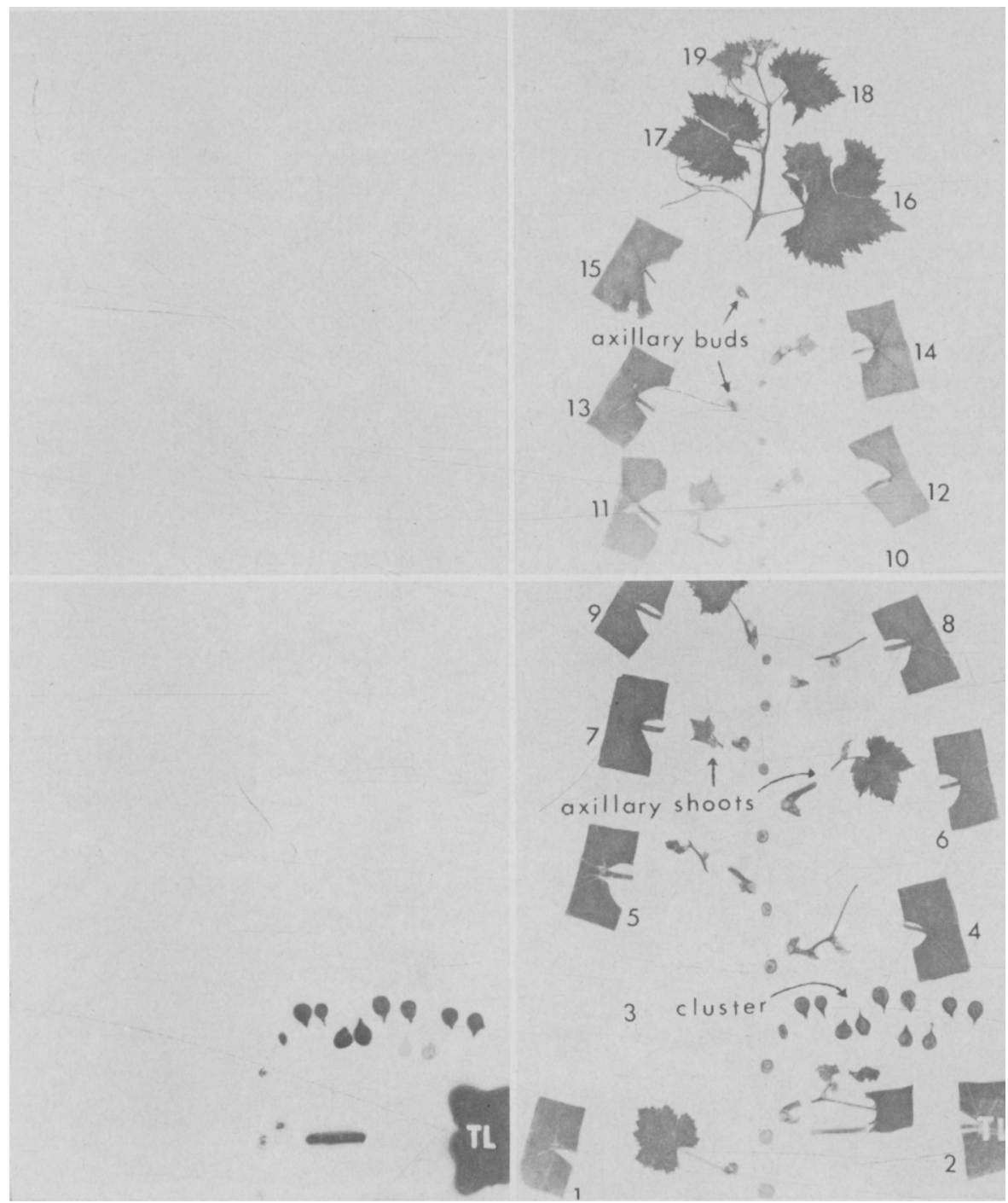

Fig. 5. Leaf number 2 treated June 7,1960 . Shoot harvested 6 hours after treatment. Left, radioautograph; right, mounted specimens. TL. Treated leaf. Translocation of activity was both acropetal and basipetal. Note that upward translocation of photosynthate proceeded no farther than the cluster.

This probably indicates that the acropetal movement was predominant. The only axillary bud to import activity was that subtended by the treated leaf. No activity was imported into the young leaves of the axillary shoot subtended by the treated leaf nor into the leaf arising at the first node.

For treatment of the middle portion of the shoot, either leaf number 8 or 9 was used. Translocation of photosynthate from leaf number 9 was practically 


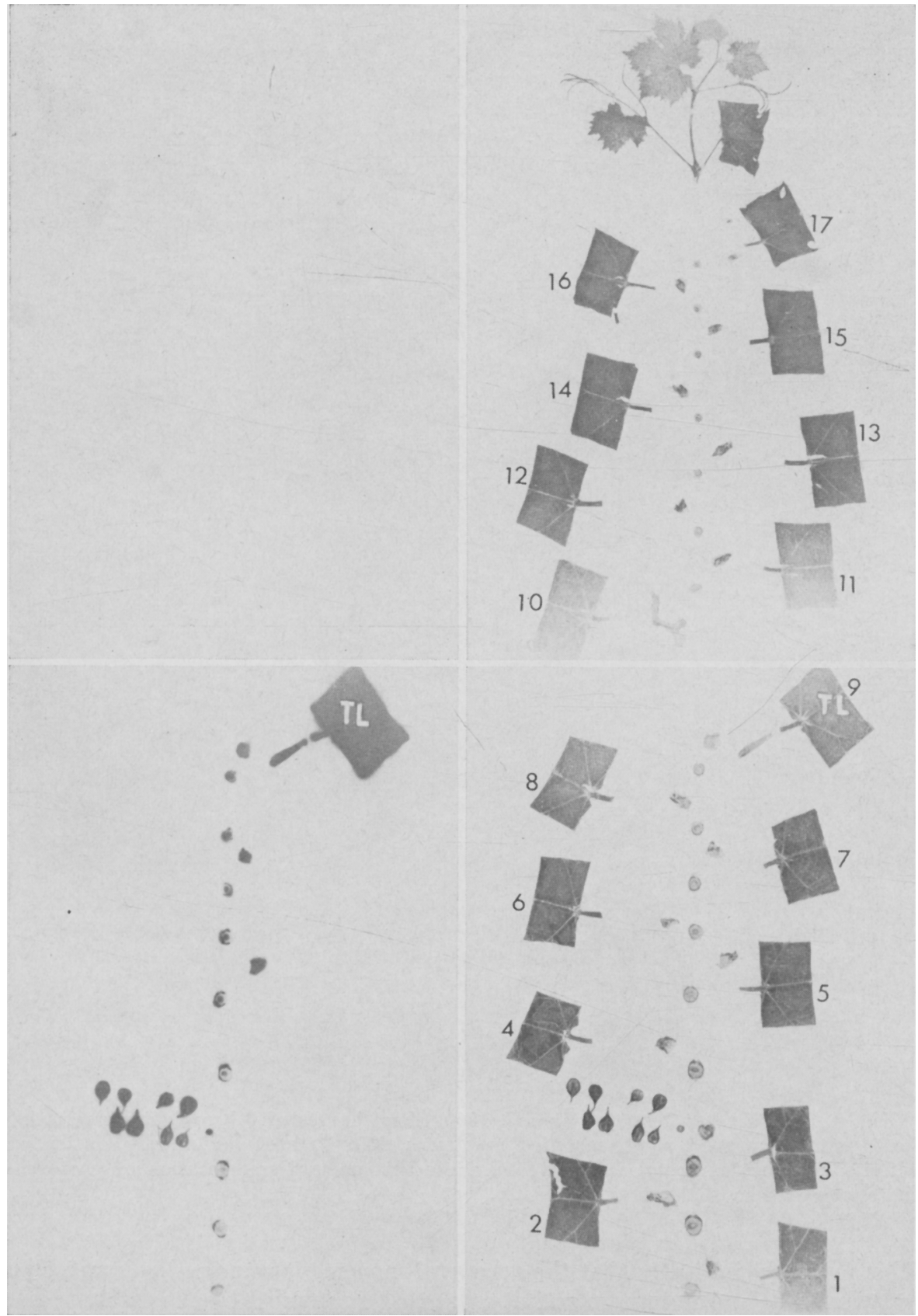

Fig. 6. Leaf number 9 treated June 10, 1960. Shoot harvested 6 hours after treatment. Left, radioautograph ; right, mounted specimens. TL. Treated leaf. Note that translocation of activity was only downwards from the treated leaf, and that only lateral buds on same side as treated leaf show much activity. 


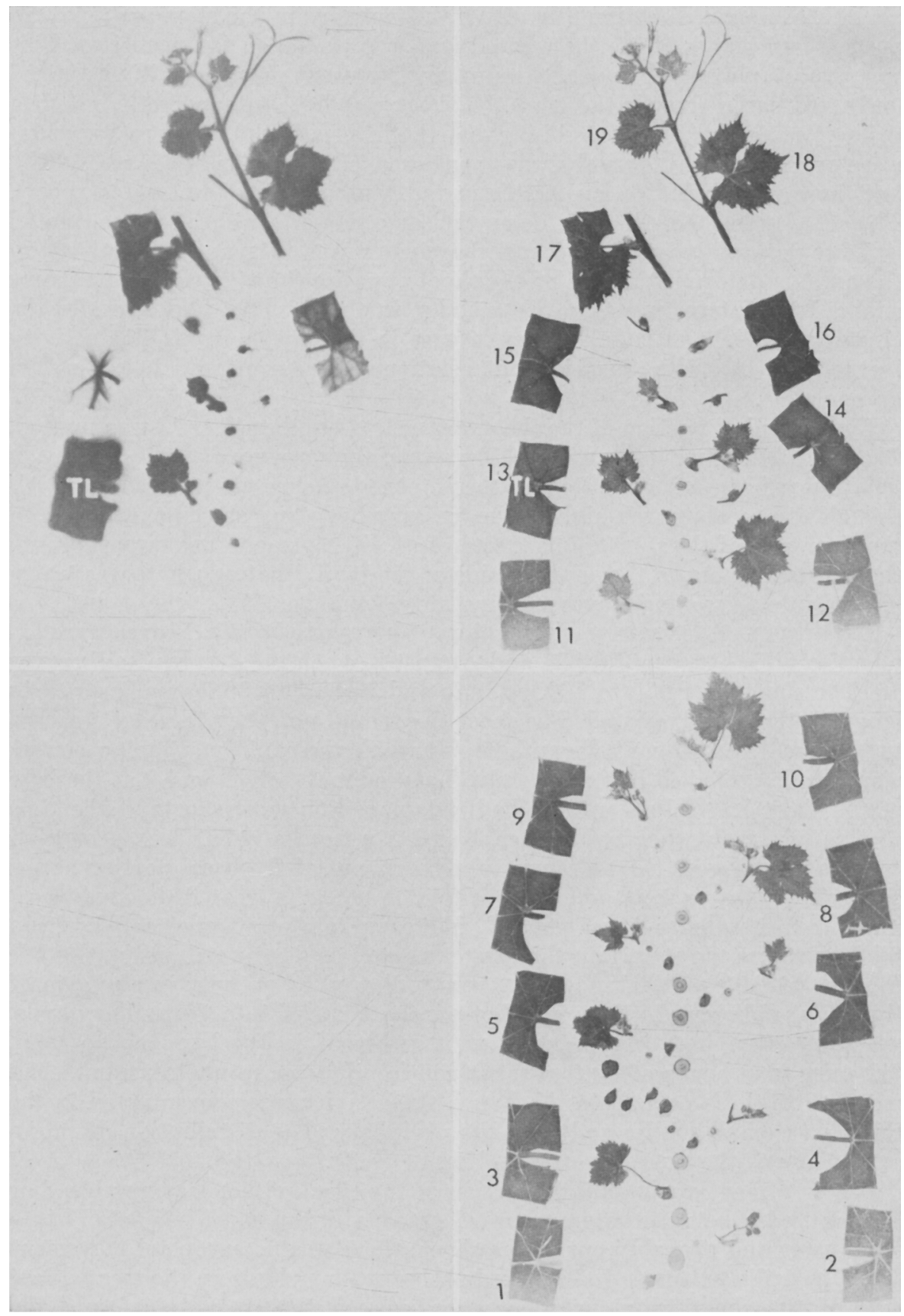

Fig. 7. Leaf number 13 treated June 7, 1960. Shoot harvested 6 hours after treatment. Left, radioautograph; right, mounted specimens. TL. Treated leaf. Translocation from the treated leaf was chiefly upwards into the shoot tip. Note that the basal movement was restricted to the internode below the treated leaf. 
all in a basipetal direction (fig. 6). Faint activity in the stem sections and mature leaf blades above the treated leaf was visible on the negatives. This was probably from $\mathrm{C}^{14} \mathrm{O}_{2}$ leakage during treatment, or from $\mathrm{C}^{14} \mathrm{O}_{2}$ respired and fixed again during the time the shoot was held in a polyethylene bag prior to mounting. The possibility that the images of the stem cross sections were pseudo-radioautographs was considered (Leonard and Weaver, 1961), but there was no indication of this in radioautographs of untreated shoots. The activity in the axillary buds on the same side of the shoot as the treated leaf between the treated leaf and the cluster was intense. The activity in the axillary buds on the side of the shoot opposite the treated leaf was very slight. It is interesting that the activity in the axillary bud opposite the cluster was slight although it was intense in the cluster itself. The activity in the bark and pith was high but relatively little appeared in the xylem parenchyma.

For the apical portion of the shoot, either leaf number 12 or 13 was treated. Translocation from leaf number 13 was mainly acropetal (fig. 7 ), the basipetal movement being limited to the internode below the treated leaf. Although radiocarbon was high in the axillary buds and shoots above and on the same side of the stem as the treated leaf, little or none was imported into the axillary shoots on the opposite side of the stem. Photosynthate was translocated into the young leaves starting at leaf number 15 .

Experiment 3 (veraison-beginning of berry ripening). Leaves were exposed to $\mathrm{C}^{14} \mathrm{O}$ 2 between July 28 and August 2, when the degrees Balling was 15. The shoots were 75 to $100 \mathrm{~cm}$ long and had 22 to 27 leaves; growth in length had virtually ceased. The shoot tips would not, therefore, be expected to be strong sinks for photosynthate, although the rapidly sugaring berries would be expected to be strong sinks. Leaves number 1,2 , and 3 at the base of the shoot had fallen or were badly damaged on most shoots at the time of this treatment. Leaves number 4 and 5 were the oldest leaves in good condition, and were therefore used for treatment of the basal portion of the shoot. These leaves were opposite clusters on both the treated shoots.

After leaf number 4 was treated, photosynthate was translocated within 6 hours across the stem into the cluster as well as downward and out of the shoot (fig. 8). The basal movement was indicated by activity in a section of the 1-year-old spur. Little or no photosynthate moved into the axillary buds, xylem parenchyma, or pith; most of it appeared in the bark of the stem. (Twenty-four hours after treatment considerably more photosynthate had moved into these parts.) In the berry, the activity was concentrated in the central vascular bundle and near the periphery. The distribution of radiocarbon among the berries was not uniform (fig. 8).

For treatment of the middle portion of the shoot, either leaf number 8 or 10 was used. Photosynthate was translocated within 6 hours basipetally into the cluster and probably out of the shoot; there was no acropetal movement (fig. 9). Radiocarbon moved into only those axillary buds on the treated leaf side of the shoot which were located between the treated leaf and the cluster. Activity in the internodes below the cluster, which appeared at node number 3, decreased with distance basal to the cluster and, in the lowermost node, was very slight except for a restricted area in the phloem. Only faint 


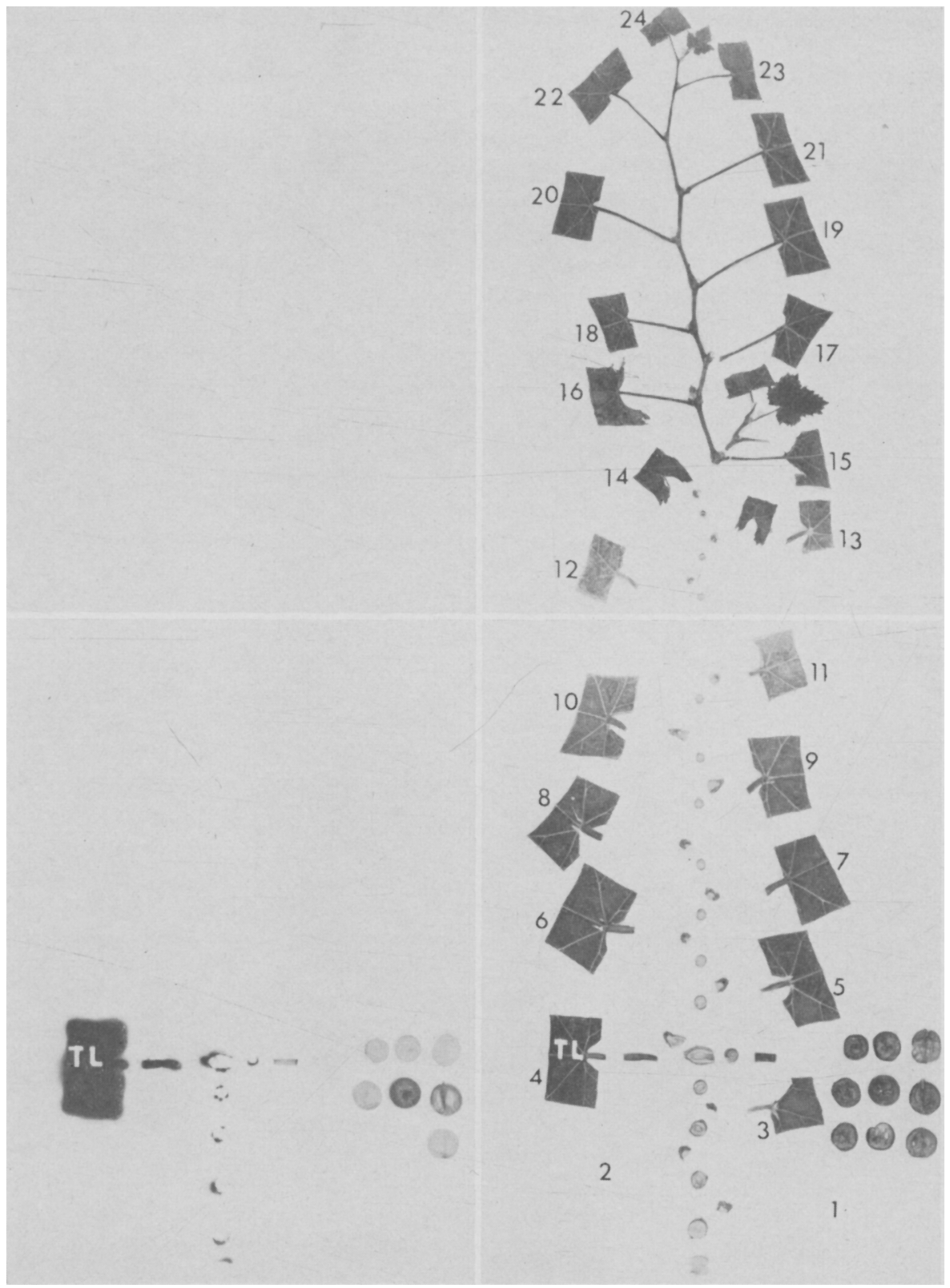

Fig. 8. Leaf number 4 treated August 2, 1960. Shoot harvested 6 hours after treatment. Left, radioautograph; right, mounted specimens. The lowest section is a cross section of the spur from which the shoot arose. TL. Treated leaf. Translocation from the treated leaf was across the stem into the cluster and down and out of the shoot. 


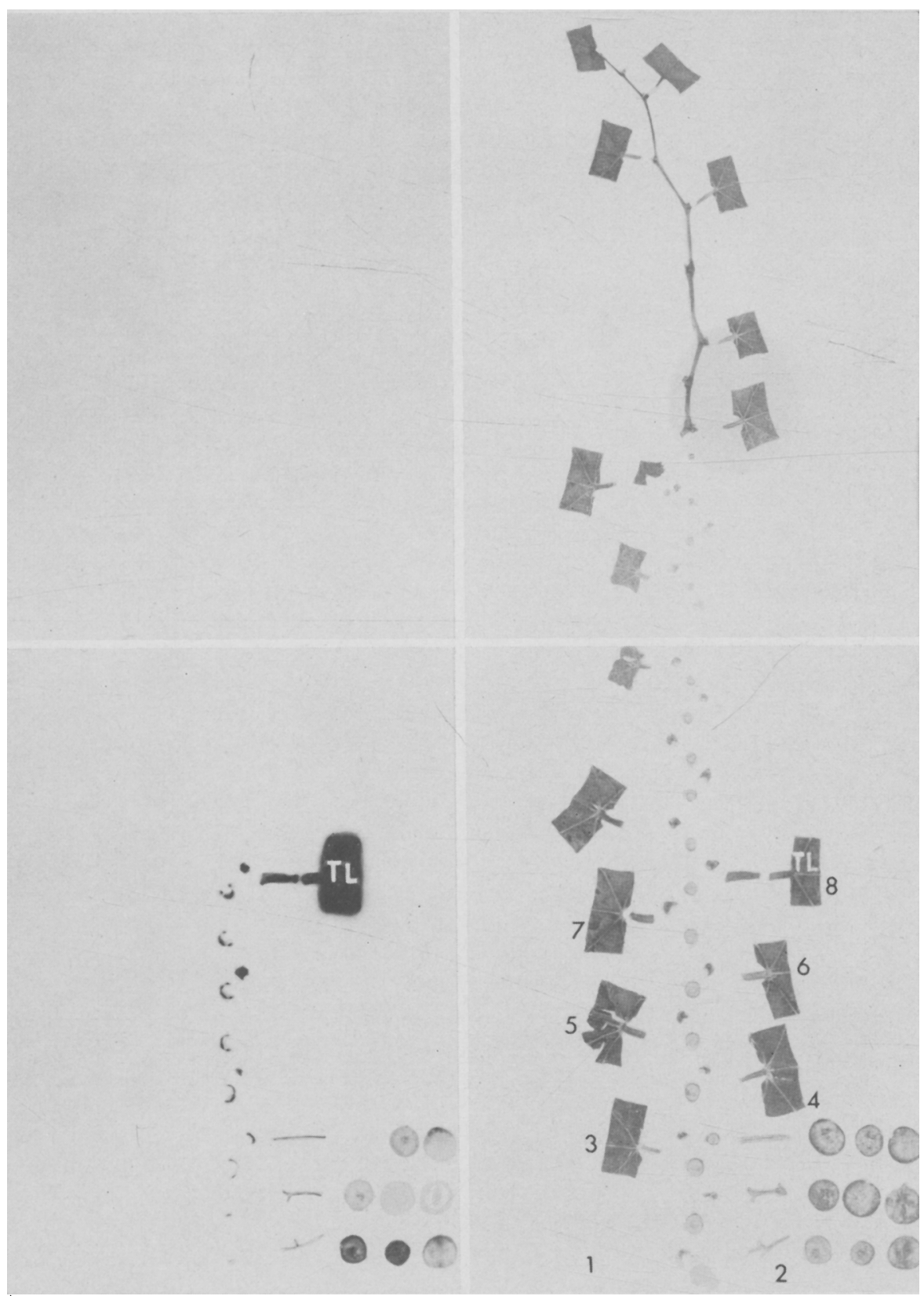

Fig. 9. Leaf number 8 treated August 2, 1960. Shoot harvested 6 hours after treatment. Left, radioautograph; right, mounted specimen. TL. Treated leaf. Translocation of photosynthate from the treated leaf was basipetal only. Note the decreasing intensity of activity in the internode sections basal to the cluster. 
activity appeared in the xylem apical to the cluster. Distribution of photosynthate among the berries was uneven.

Radioautographs of shoots harvested 24 hours after treatment showed a similar distribution of radiocarbon as did those of shoots harvested after 6 hours, except that in the longer experimental period relatively more activity appeared in the xylem rays and the axillary buds. There was less activity in the fruit on the shoot harvested 24 hours after treatment than on the shoot harvested after 6 hours. In the shoot harvested at 24 hours, a greater portion of the radiocarbon appeared to be moving downward in the phloem below the cluster. A possible explanation is that the treated leaf on this shoot was on the opposite side of the stem from the cluster, whereas the treated leaf on the shoot harvested at 6 hours was on the same side of the stem as the cluster.

For treatment of the apical portion of the shoot about $10 \mathrm{~cm}$ of the shoot tip were exposed to $\mathrm{C}^{14} \mathrm{O}_{2}$. Within 6 hours, photosynthate was translocated basipetally into the axillary buds on the younger parts of the shoot, into the cluster, and probably out of the shoot. When shoots were not removed from the vine until 24 hours after treatment, activity increased in the axillary buds in the middle and lower portions of the shoot and in the xylem rays (fig. 10).

Experiment 4 (harvest stage). Shoots were treated between September 7 and 13, when they were about 90 to $100 \mathrm{~cm}$ long and had 25 to 27 leaves. The degrees Balling of the fruit was 21 .

For the basal treatment, $\mathrm{C}^{14} \mathrm{O}_{2}$ was applied to leaf number 2 of one shoot which was harvested 6 hours after treatment. The photosynthate moved apically into the cluster, but there was no movement beyond it (fig. 11). Photosynthate also moved basipetally and out of the shoot. In a second shoot (radioautograph not shown) harvested 24 hours after treatment, the leaf opposite the cluster was treated. Here the movement of the photosynthate was across the stem into the cluster, and downward and out of the shoot. With the exception of the bud in the axil of the treated leaf, no activity appeared in the lateral buds of shoots harvested either 6 or 24 hours after treatment.

For treatment of the middle portion of the shoot, $\mathrm{C}^{14} \mathrm{O}_{2}$ was applied to leaf number 9 . Within 6 hours photosynthate had moved basipetally out of the shoot (fig. 12). Photosynthate moved into the cluster and into the axillary buds located between the treated leaf and the cluster on the same side of the stem as the treated leaf. Buds between the cluster and the base of the shoot on the same side of the stem as the cluster also showed activity. Translocation across the stem to the cluster apparently occurred at the fruit node. The location of axillary buds showing activity was influenced by the position of the cluster on the opposite side of the stem from the treated leaf. The distribution of radiocarbon on a second shoot harvested 24 hours after treatment was similar to that harvested after 6 hours except that there appeared to be relatively more activity in the xylem rays at the later harvest.

For treatment of the apical portion, the terminal 7 to $10 \mathrm{~cm}$ bearing six leaves were exposed to $\mathrm{C}^{14} \mathrm{O}_{2}$. The photosynthate was translocated basipetally into the cluster and out of the shoot within 6 hours (fig. 13). In many internode sections apical to the cluster, the photosynthate appeared in two bands on opposite sides of the stem, but, basal to the cluster, it was in one semi- 

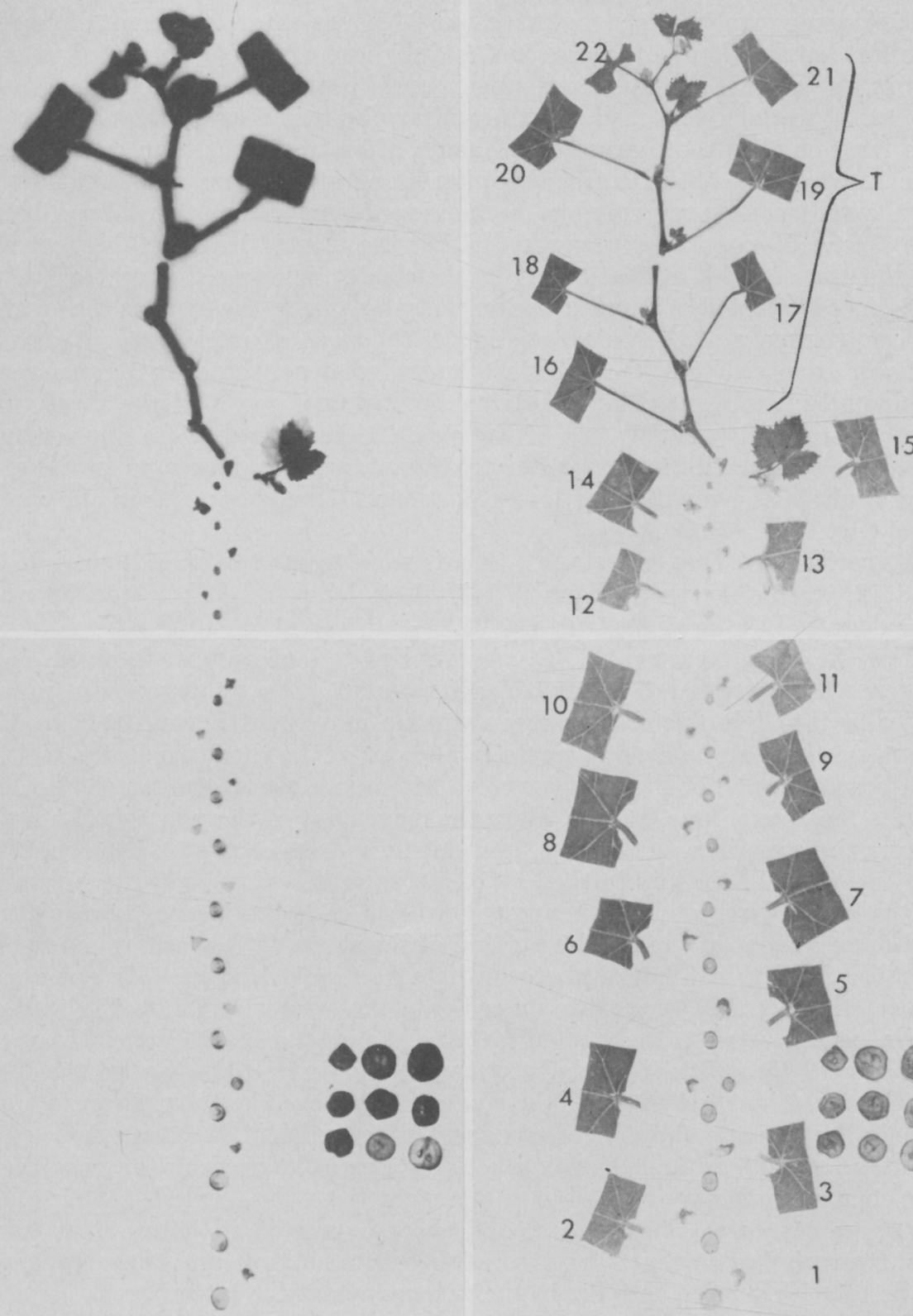

\section{5}
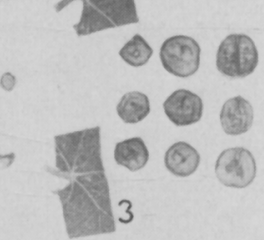

1

Fig. 10. Shoot tip treated on August 2, 1960. Shoot harvested 24 hours after treatment. Left, radioautograph; right, mounted specimens. T. Treated shoot. Note high activity in the eluster and the axillary buds. 


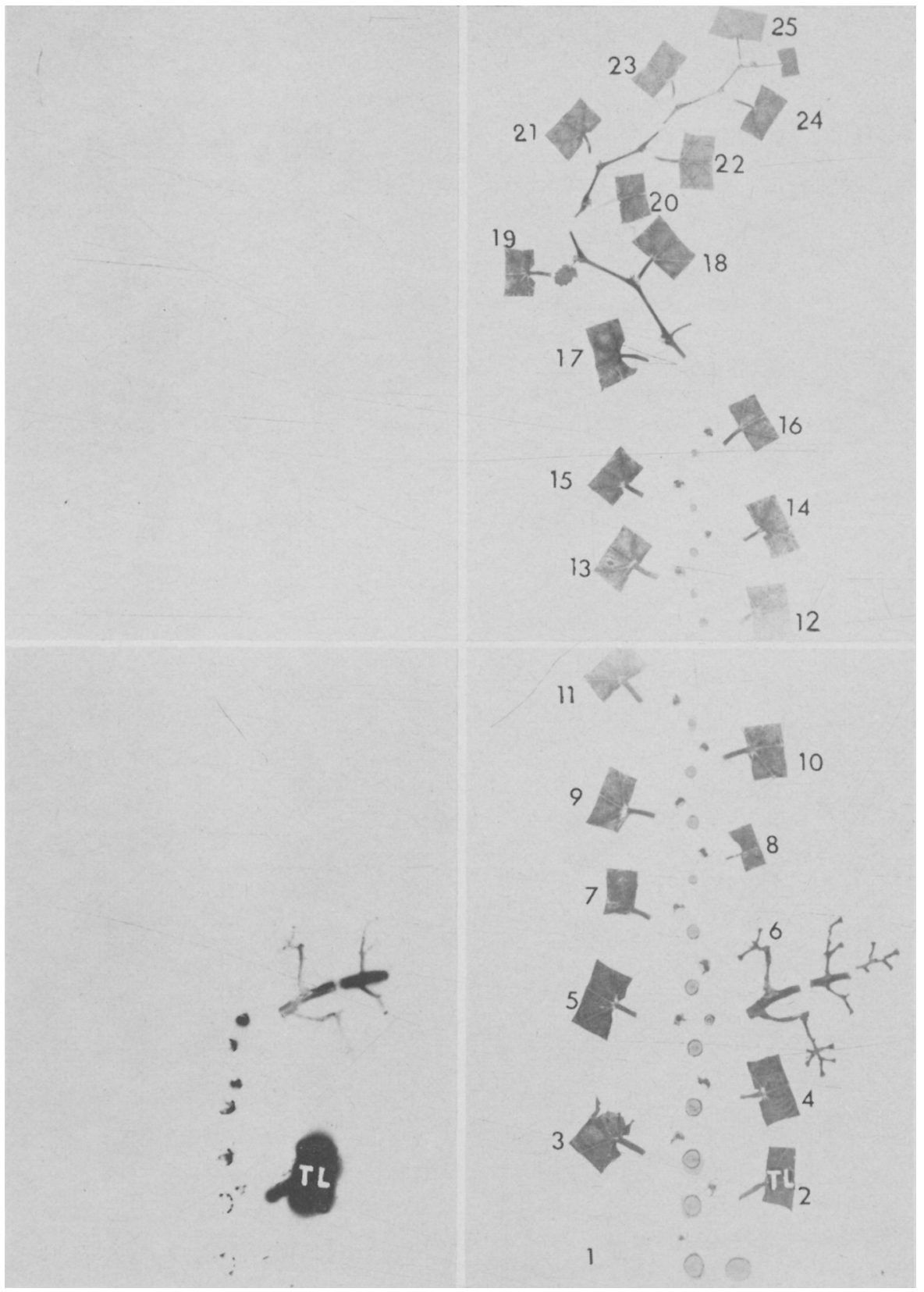

Fig. 11. Leaf number 2 treated September 7, 1960. Shoot harvested 6 lours after treatment. Left, radioautograph; right, mounted specimen. TL. Treated leaf. The lower right stem section is a cross section of the spur. Translocation from the treated leaf was upward into the cluster and downward and out of shoot. Note that no photosynthate moved into the axillary buds on the side of the shoot opposite the treated leaf. 


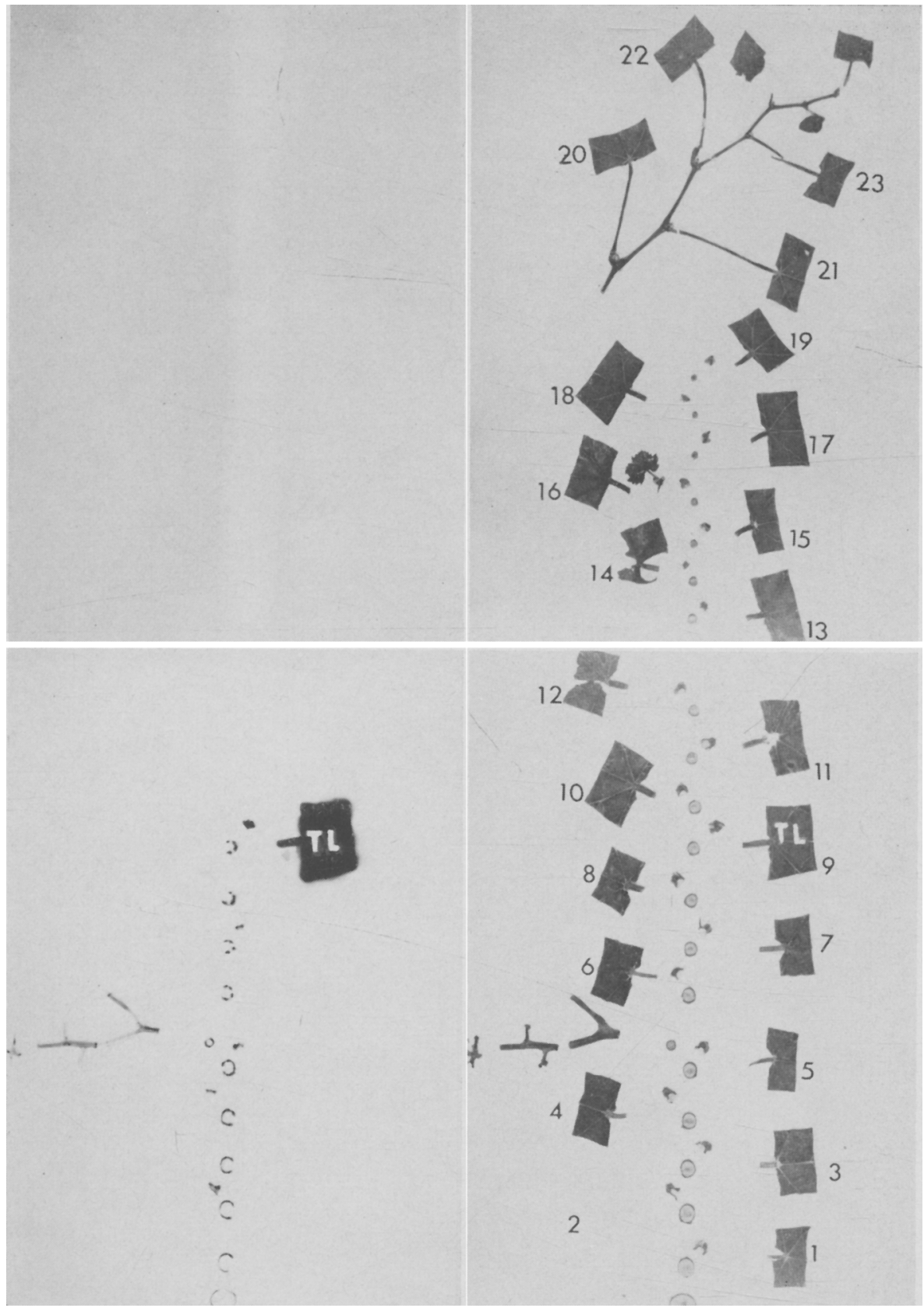

Fig. 12. Leaf number 9 treated on September 7, 1960. Shoot harvested 6 hours after treatment. Left, radioautograph; right, mounted specimens. TL. Treated leaf. The lowest cross section is from the spur. Photosynthate was translocated from the treated leaf downward into the cluster and out of the shoot. Note the activity in the axillary buds above the cluster on the treated side of the shoot, and in those below the cluster on the side of the shoot opposite the treated side. 


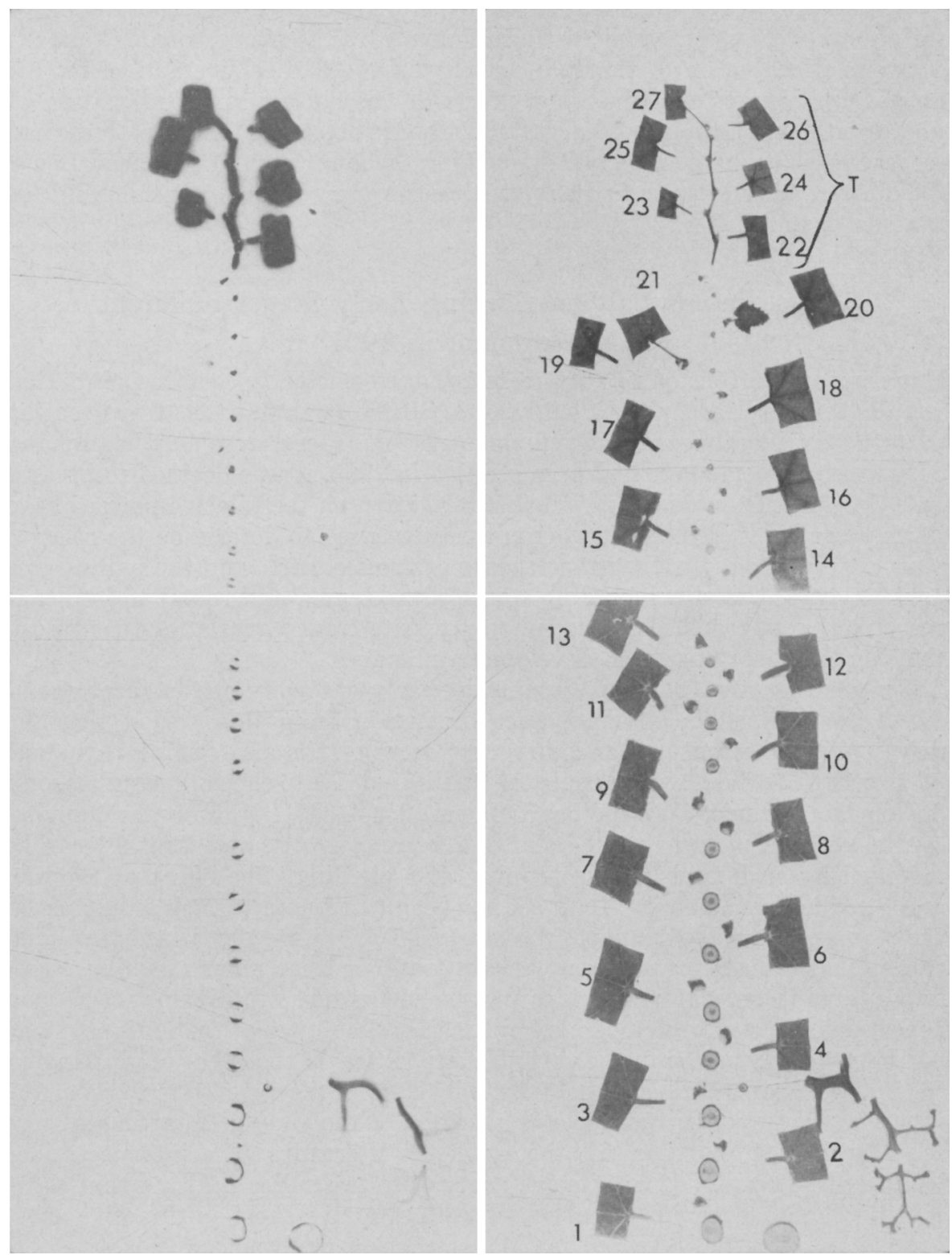

Fig. 13. Shoot tip treated on September 12, 1960. Shoot harvested 6 hours after treatment. Left, radioautograph; right, mounted specimens. T. Treated shoot. The lower right cross section is a segment of the spur. Translocation from the treated shoot tip was downward into the cluster and out of the shoot. Note activity in the axillary buds on the upper part of the shoot, but its absence in buds on the older part of the shoot. 
circular band on the same side as the cluster. The internode sections below the cluster were oriented correctly in figure 13 . It seems reasonable that the different distribution of the radioactivity in the bark above and below the cluster was due to the diverting effects of the cluster on translocation of photosynthate. In the shoot harvested 24 hours after treatment, activity had increased in the xylem rays, particularly in the lower part of the shoot. Below the cluster, activity appeared only in those axillary buds on the same side of the stem as the cluster.

\section{Translocation Patterns During Early Stages of Shoot Development in 1961}

Experiments performed in 1961 were designed to clarify certain points that were not made clear by the 1960 results. Since it was felt that translocation patterns during the early development of the shoot were important, and only one prebloom stage had been studied in 1960, it was decided to investigate this stage in more detail. More information on the relative power of the sinks was also needed. Experiments were designed to determine the relative power of the shoot tip, the inflorescence or fruit cluster, and the parent vine (older part of the vine including spurs, arms, trunk, and roots) to influence the direction of translocation of photosynthate from leaves at different positions on the shoot at several developmental stages.

The translocation patterns during the early ontogeny of the shoot are of particular physiological importance because it is in this period that the flower parts differentiate, and flowering occurs. It is also during this stage of growth that the flower initials that will give rise to the following season's flowers are formed (Winkler and Shemsettin, 1937). Flower development can be affected by varying the leaf/inflorescence ratio, and fruit set can be modified by such practices as topping and girdling. The effect of topping and girdling on increasing fruit set has been attributed to their influence on the supply of carbohydrates to the cluster. The assumption in this explanation is that the cluster requires carbohydrate, or some other assimilate, perhaps a growth regulator, which cannot be adequately supplied under normal conditions for vine growth. This implies that the flower at the fruit set stage competes poorly as a sink for various metabolites. If the effect of girdling on set is a result of a higher carbohydrate level, then the vegetative parts of the vine may be important and powerful sinks at the time of flowering. There are few data supporting this theory in the literature. The interpretations based on the results of correlative carbohydrate studies indicate that there is little or no movement of carbohydrate out of the shoot until active shoot growth has greatly decreased. At Davis, shoot growth normally is much reduced by the end of June.

Treatments with $\mathrm{C}^{14} \mathrm{O}_{2}$ were made at each of six developmental stages between bud burst and the end of flowering. At each stage, from two to four experiments were performed, each using a leaf at a different position on the shoot, to determine the influence of position and developmental stage on translocation patterns. At a given stage all treated leaves were nearly full size, but their ages varied. Six hours after exposure of the leaves to the labeled 
carbon dioxide the shoots were harvested, mounted, and radioautographed. Work in 1960 had shown that a 6-hour interval between treatment and harvest was sufficient to produce good radioautographs. Harvesting shortly after treatment also minimized metabolic changes of the $\mathrm{C}^{14}$-labeled compounds and their probable redistribution.

An attempt was made to select leaves which had just started exporting carbohydrate for exposure to the $\mathrm{C}^{14} \mathrm{O}_{2}$. When the young leaf of the Muscat shoot emerges from the bud it turns a characteristic bronze color. As the leaf grows, it loses this bronze coloration and becomes light green. The leaf at this stage is thin and delicate in texture. With further growth, the leaf

TABLE 1

GROWTH IOATA ON BASAL THIRTEEN LEAVES IN GRAPEVINE SHOOTS (Average values from eleven replicate shoots)

\begin{tabular}{|c|c|c|c|}
\hline \multirow[b]{2}{*}{ Leaf number* } & \multirow[b]{2}{*}{$\begin{array}{l}\text { Date when growth } \\
\text { stopped }\end{array}$} & \multicolumn{2}{|c|}{ Final size of leaf blade $\dagger$} \\
\hline & & $\begin{array}{l}\text { Length of blade } \\
(\mathrm{cm})\end{array}$ & $\begin{array}{c}\text { Length of lower lobe } \\
\text { of blade } \\
(\mathrm{cm})\end{array}$ \\
\hline $1 \ldots \ldots \ldots \ldots \ldots \ldots \ldots \ldots \ldots \ldots \ldots$ & May 2 & 5.7 & 3.6 \\
\hline $2 \ldots \ldots \ldots \ldots \ldots \ldots \ldots \ldots \ldots \ldots \ldots$ & May 2 & 7.0 & 4.9 \\
\hline$\ldots \ldots \ldots \ldots \ldots \ldots$ & May 8 & 8.5 & 6.0 \\
\hline $4 \ldots \ldots$ & May 14 & 8.5 & 6.0 \\
\hline ....... & May 14 & 9.0 & 5.5 \\
\hline $6 \ldots \ldots \ldots$ & May 22 & 8.5 & 5.5 \\
\hline 7. & May 29 & 8.5 & 5.5 \\
\hline $8 \ldots$ & May 29 & 8.5 & 5.5 \\
\hline $9 \ldots$ & May 29 & 8.0 & 5.6 \\
\hline $10 \ldots$ & June 6 & 8.0 & 5.5 \\
\hline$\ldots \ldots \ldots \ldots$ & June 14 & 8.0 & 6.0 \\
\hline $12 \ldots \ldots \ldots \ldots$ & June 14 & 7.0 & 5.0 \\
\hline $13 \ldots \ldots \ldots \ldots \ldots \ldots, \ldots \ldots \ldots \ldots \ldots$ & June 22 & 7.0 & 5.0 \\
\hline
\end{tabular}

\footnotetext{
* Leaf number 1 is basal leaf, etc.

+ Length of blade was measured from the junction of the petiole and the leaf blade to the tip of the main vein. Length of lower lobe was measured from the junction of the petiole and leaf blade to the tips of the lower lateral lobe.
}

becomes much rougher in texture and turns dark green, the color of the mature leaves. It was thought that a light-green, soft-textured leaf was still nutritionally dependent on the shoot. The most mature light green leaf was referred to as the "oldest juvenile leaf," and was used as a reference point for the selection of leaves for treatment with $\mathrm{C}^{14} \mathrm{O}_{2}$. If the length of the shoot permitted, leaves at the first, second and occasionally the third node below the "oldest juvenile leaf" were exposed to the labeled carbon dioxide. It was found subsequently that the "oldest jurenile leaf" was an exporting leaf and thus not a satisfactory reference point on the shoot. There was no way to determine whether the leaf apical or basal to the treated leaf was also exporting. The position of the treated leaf is therefore designated by leaf number and by the approximate number of nodes from shoot apex.

Concurrently with the experiments using $\mathrm{C}^{14} \mathrm{O}_{2}$, shoot, leaf, and cluster measurements on eleven other selected shoots were made at approximately weekly intervals from April 15, when the shoots were about $10 \mathrm{~cm}$ long and 
had 5 to 6 expanding leaves, until June 22, when the shoots were about $80 \mathrm{~cm}$ long and had about 23 leaves (table 1 gives the average values of the eleven shoots). Leaf number 1 reached maximum size by May 2 and leaf number 13 by June 22 .

For the individual treated shoots, the stage of growth and positions of the treated leaves at the various times of treatment are given in table 2 . The

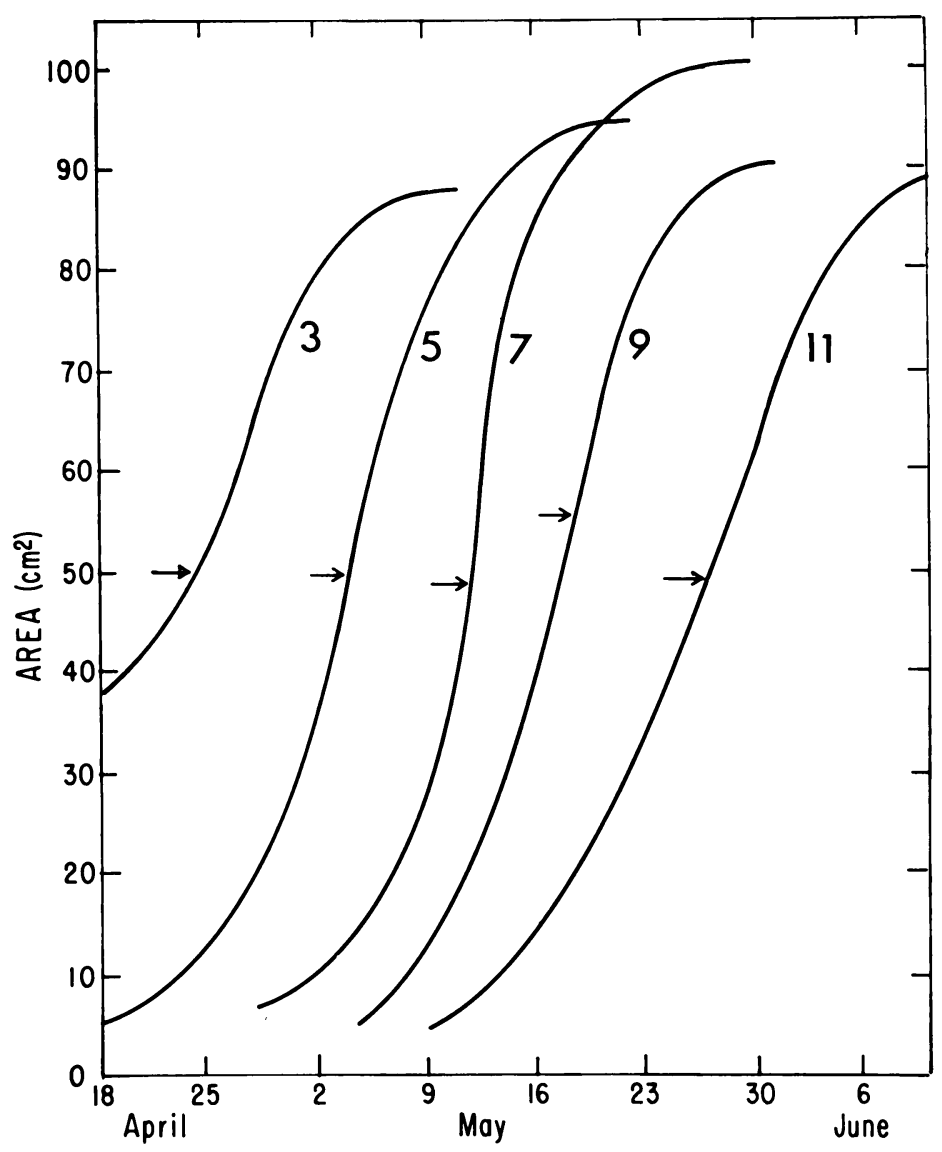

Fig. 14. Average of growth curves of eleven shoots as indicated by increase in area of leaves number $3,5,7,9$, and 11 , showing the date (indicated by arrow) on which the leaves started exporting.

number of leaves shown to have attained their full size on shoots treated with $\mathrm{C}^{14} \mathrm{O}_{2}$ were calculated from values obtained from the growth measurements in table 1.

Leaf and cluster growth. The leaves displayed a typical sigmoid growth curve, as shown in figure 14, which gives the average measurements for the eleven shoots mentioned above. The most rapid expansion in area for leaf number 3 occurred in the first week after the leaves unfolded, and the most rapid expansion for the other leaves in the second and third weeks. The 
leaves started exporting photosynthate when they were about one half of their final area (see arrows in fig. 14). At this stage of growth there were usually 3 to 5 younger importing leaves on the shoot.

The average lengths of the eleven clusters measured on May 2, May 9, May 14, May 22, May 29, and June 6 were 16.5, 20.6, 24.5, 25.5, 27.7, and $28.2 \mathrm{~cm}$ respectively. The growth in length was much less after May 14, which was about 10 days before bloom.

First developmental stage. At the treatment on April 15, the shoots were 10 to $15 \mathrm{~cm}$ long and had 5 or 6 leaves, none of which were fully expanded (table 2). The larger shoots on the vine were selected because the smaller ones

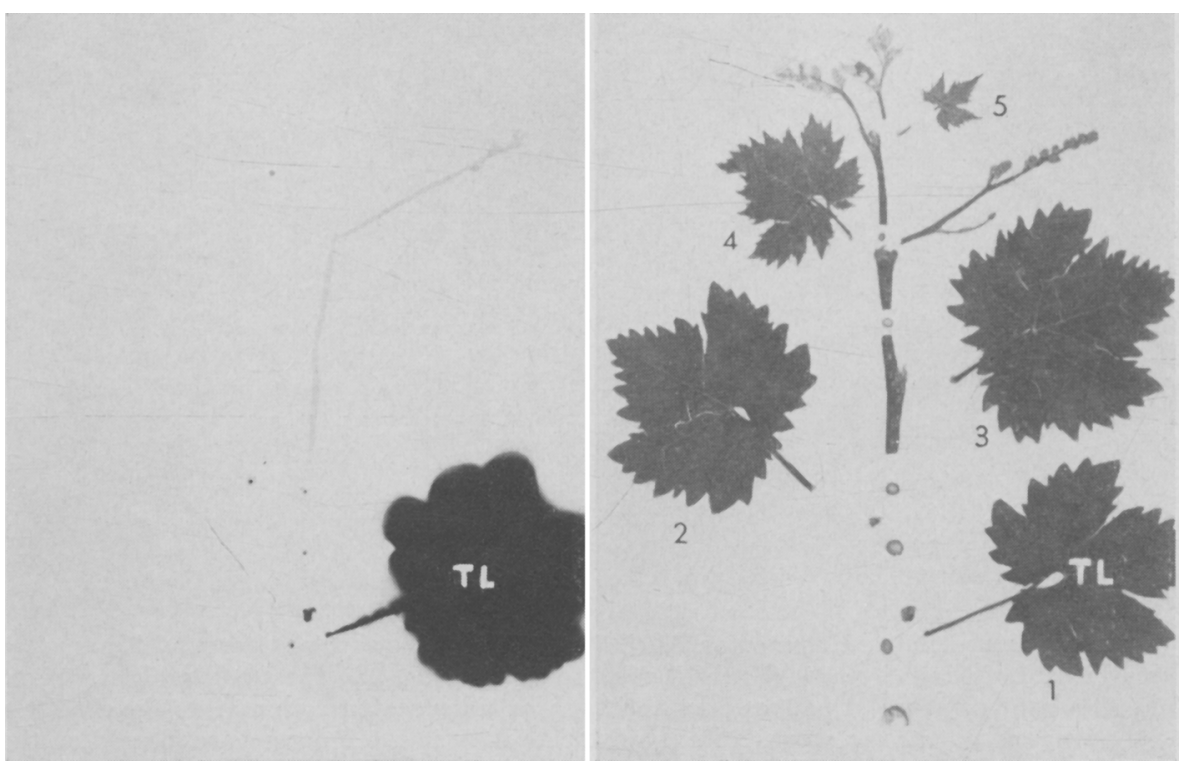

Fig. 15. Leaf number 1 treated on April 15, 1961, and the shoot harvested 6 hours after treatment. Left, radioautograph; right, mounted specimens. TL. Treated leaf. Note the faint activity in the inflorescence, and intense activity in the axillary bud of the treated leaf.

were fragile and difficult to manipulate without damaging them. Either the first or second leaf on the shoot, about five nodes basal to the shoot apex, was treated.

Translocation from leaf number 1 was acropetal (fig. 15), but only a small amount of radiocarbon moved out of the treated leaf. Much radiocarbon moved into the bud in the axil of the treated leaf, but only faint activity appeared in the inflorescence at the fourth node. The activity in the stem was faint and it occurred mainly on the same side of the stem as the treated leaf. No photosynthate was translocated out of leaf number 2 of another treated shoot even though this shoot was slightly larger than the shoot on which leaf number 1 was treated.

Second developmental stage. Treatment was made on April 25 (table 2). The oldest leaves were still expanding and lacked about 1 week of attaining 
full size. Treatment of leaf number 1 , which was about seven nodes basal to the shoot apex, showed that translocation of photosynthate from it was both acropetal and basipetal (fig. 16). The upward movement took radiocarbon into the axillary buds at the first, third, and fifth nodes and also into the younger leaves starting at leaf number 4 . The activity in the inflorescence, which was on the opposite side of the shoot from the treated leaf, was slight.

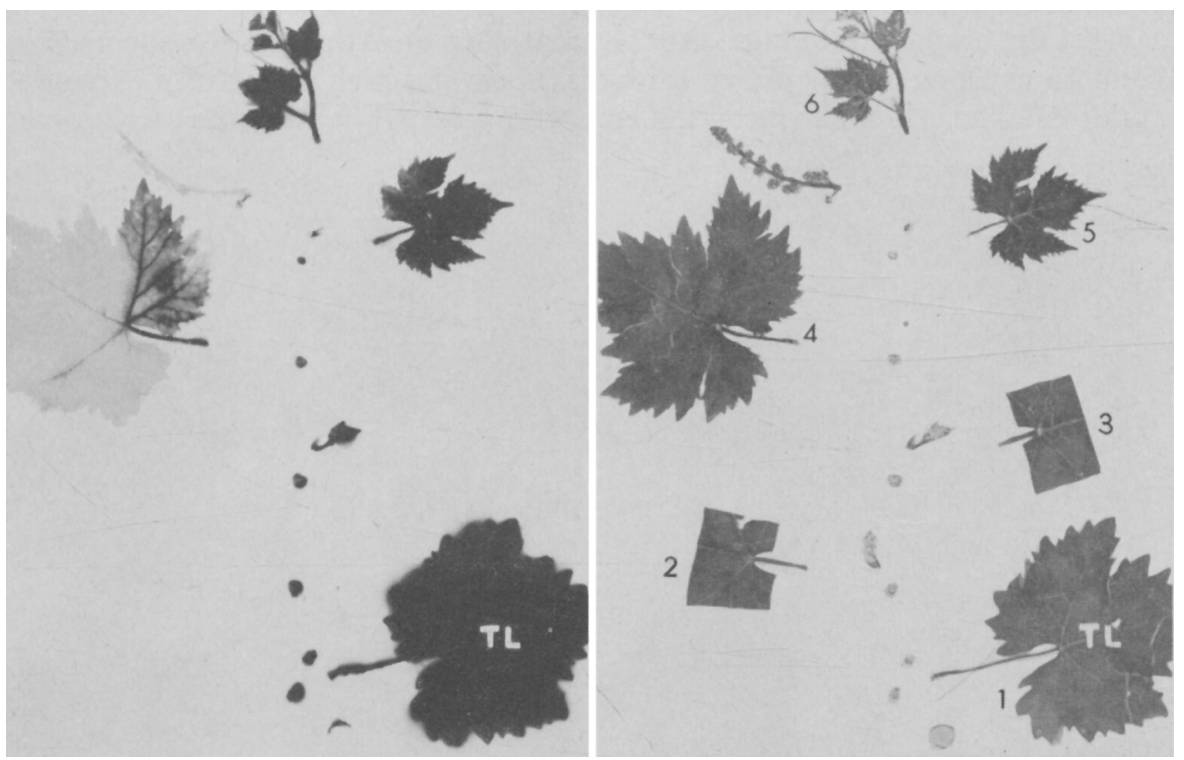

Fig. 16. Leaf number 1 treated on April 25, 1961, and the shoot harvested 6 hours after treatment. Left, radioautograph; right, mounted specimens. TL. Treated leaf. Lower right cross section is a segment of the spur. Activity was translocated both up into the shoot tip and down and out of the shoot. Note the faint activity in the inflorescence located on the side of the stem opposite to the treated leaf.

In a second and third replicate shoot, either leaf number 1 or 2 , five nodes basal to the shoot apex, was treated. The activity in the inflorescences on the same side of the stem as the treated leaf in these shoots was intense. These results show strikingly that there is often much greater translocation of elaborated food materials into organs on the same side of the stem as the exporting leaf.

Third developmental stage. On May 4, the shoots were about $30 \mathrm{~cm}$ long and had 8 to 9 leaves (table 2). The second leaf was mature and the third and fourth leaves were calculated to reach full size 4 and 10 days later, respectively. Translocation patterns were essentially the same as those obtained on April 25. In one shoot the tendril on the same side of the stem as the treated leaf showed much activity, but that on the opposite side showed none even though it was younger and would be expected to be a stronger sink.

Fourth developmental stage. Shoots were treated on May 12 (table 2). In general, results were the same as those of April 25 and May 4 . In one replicate 
shoot, leaf number 5, eight nodes basal to the shoot apex, was exposed to $\mathrm{C}^{14} \mathrm{O}_{2}$. No activity was detected in the inflorescence one node below the treated leaf. However, in a second replicate shoot, when leaf number 5 , nine nodes below the shoot apex, was treated, a small amount of photosynthate moved into the inflorescence on the opposite side of the stem from the treated leaf.

Fifth developmental stage. Shoots were treated on May 19 just before flowering started (table 2). Leaf number 7 was almost full size and was treated on two shoots.

TABIE 2

GROWTH DATA ON GRAPEVINE SHOOTS TREATED WITH C $\mathrm{C}^{1-4} \mathrm{O}_{2}$ IN 1961

( Two to four shoots treated at each stage)

\begin{tabular}{|c|c|c|c|c|}
\hline $\begin{array}{r}\text { Date of } \\
\text { treatment }\end{array}$ & $\begin{array}{l}\text { Treated leaf } \\
\text { number }\end{array}$ & $\begin{array}{l}\text { Shoot length } \\
(\mathrm{cm})\end{array}$ & $\begin{array}{l}\text { Number of } \\
\text { leaves }\end{array}$ & $\begin{array}{c}\text { Number of } \\
\text { fully expanded } \\
\text { leaves }\end{array}$ \\
\hline $\begin{array}{l}\text { April } 15 \ldots \ldots \ldots \ldots \\
\quad \text { 1st stage }\end{array}$ & $1^{*}, 2$ & $10-15$ & $5-6$ & 0 \\
\hline $\begin{array}{l}\text { April } 25 \ldots \ldots \ldots \ldots \\
\text { 2nd stage }\end{array}$ & 1,2 & $15-20$ & $5-7$ & 0 \\
\hline $\begin{array}{l}\text { May } 4 \ldots \ldots \ldots \ldots \ldots \\
\text { 3rd stage }\end{array}$ & $2,3,4$ & 30 & $8-9$ & 2 \\
\hline $\begin{array}{l}\text { May } 12 \ldots \ldots \ldots \ldots \\
\quad 4 \text { th stage }\end{array}$ & 4,5 & $40-50$ & $9-12$ & $4-5$ \\
\hline $\begin{array}{l}\text { May } 19 \ldots \ldots \ldots \ldots \\
\text { 5th stage }\end{array}$ & $7,7,6$ & $50-55$ & $13-14$ & $5-6$ \\
\hline $\begin{array}{l}\text { May } 26 \ldots \ldots \ldots \ldots \ldots \ldots \ldots \ldots \ldots \\
\text { 6th stage }\end{array}$ & $2,6,8,9$ & 60 & $15-17$ & 7-9 \\
\hline
\end{tabular}

${ }^{*}$ Leaf number 1 is basal leaf, etc.

Translocation of $\mathrm{C}^{14}$ from one leaf about ten nodes below the shoot apex was in a basipetal direction only. Presence of activity in the spur showed that photosynthate moved out of the shoot. Photosynthate moved only into those axillary buds located on the same side of the stem as the treated leaf. No photosynthate moved into the inflorescence which was on the opposite side of the stem and three nodes below the treated leaf. In the second shoot, leaf number 7 was about eight nodes basal to the shoot apex. In this case movement of photosynthate was both acropetal and basipetal (fig. 17). Translocation upwards carried activity into axillary buds and shoots and the young leaves starting at leaf number 11, which was about four nodes below the shoot apex. The basipetal translocation took photosynthate out of the shoot, but none moved into the second shoot on the spur. This shoot was basal to the treated shoot. Activity appeared in the axillary bud at the second node below the treated leaf, and to a very slight degree, in the peduncle and flower cluster. Both structures were on the same side of the stem as the treated leaf. In a third replicate shoot, leaf number 6 , eight nodes below the shoot apex, was treated. Translocation of photosynthate was mainly acropetal.

Sixth developmental stage. The final series of shoots was treated on May 26 , when flowering was almost completed (table 2 ). The largest leaf usually arose at the seventh node. Translocation of $\mathrm{C}^{14}$ from leaves number 2 and 6 
was entirely basipetal and out of the shoot into the older parts of the vine, as indicated by the activity in the spur.

When leaf number 8 , seven nodes below the shoot apex, was treated, translocation of the photosynthate was in both directions, but the acropetal movement appeared predominant. In the fourth replicate shoot, leaf number 9,
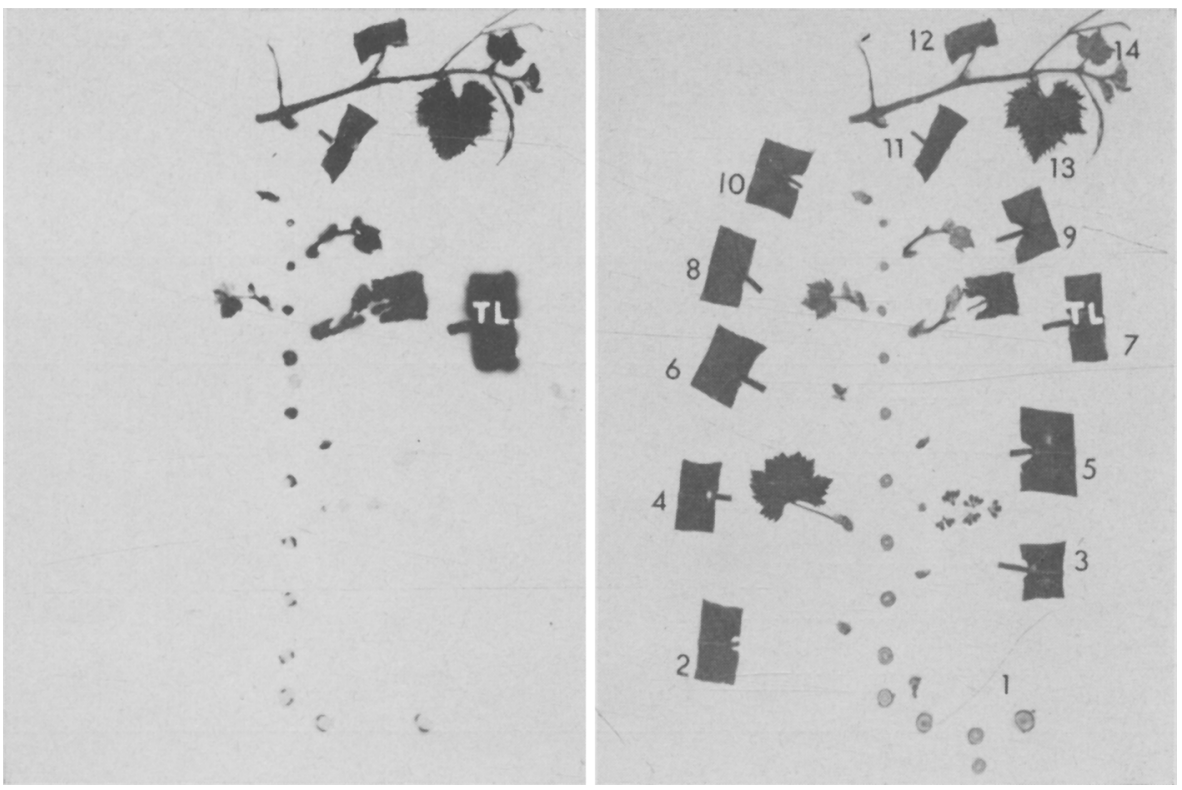

Fig. 17. Leaf number 7 treated on May 19, 1961, and shoot harvested 6 hours after treatment. Left, radioautograph; right, mounted specimens. TL. Treated leaf. The three sections at bottom right are, from left to right, spur, shoot arising from the spur basal to the treated shoot, and section of spur. Translocation from the treated leaf was bidirectional but the acropetal movement was predominant. Note that activity in the peduncle and cluster is very faint.

eight nodes below the shoot apex, was treated. Translocation was again in both directions, but here, the basipetal movement appeared to be greater than in the shoot where leaf number 8 was treated.

\section{Translocation Patterns on Partially Defoliated Shoots in 1961}

Experiments on partially defoliated shoots were designed to determine the relative power of the shoot tip, the inflorescence or fruit cluster, and the parent vine as sinks for photosynthate. All leaves were removed except one mature leaf for treatment, which was either below, opposite, or above the inflorescence, and the young leaves at the shoot tip. The shoot tip was 12 to $15 \mathrm{~cm}$ long and consisted of four to six rapidly growing leaves. The shoots were defoliated to remove all influences on translocation except the one treated leaf, the source, and the three main sinks: shoot tip, cluster, and 
parent vine. In this way it was hoped to eliminate the complicating effects of other exporting leaves.

Shoots were defoliated 2 days before treatment with $\mathrm{C}^{14} \mathrm{O}$, so that the wounds would heal, and the new translocation pattern be set in motion. It was thought that lateral buds, which would complicate the pattern, would not emerge after only 2 days. The retained mature leaves were treated with $\mathrm{C}^{14} \mathrm{O}_{2}$ at each of five different developmental stages between May 18, about 1

TABLE 3

GROWTH DATA ON GRAPEVINE SHOOTS USED IN IDEFOLTATION EXPERIMENTS IN 1961

( Three shoots treated at each stage)

\begin{tabular}{|c|c|c|c|c|c|}
\hline$\underset{\text { treatment }}{\text { Date of }}$ & $\begin{array}{c}\text { Treated } \\
\text { leaf number }\end{array}$ & $\begin{array}{l}\text { Shoot length } \\
(\mathrm{cm})\end{array}$ & $\begin{array}{l}\text { Number } \\
\text { of leaves }\end{array}$ & $\begin{array}{c}\text { Number of } \\
\text { mature } \\
\text { leaves }\end{array}$ & $\begin{array}{c}\text { Stage of } \\
\text { cluster } \\
\text { development }\end{array}$ \\
\hline $\begin{array}{l}\text { May } 18 \ldots \ldots \ldots \ldots \\
\text { 1st stage }\end{array}$ & $2,5,8$ & 60 & 14 & $6-7$ & Prebloom \\
\hline $\begin{array}{c}\text { May } 30 \ldots \ldots \\
\text { 2nd stage }\end{array}$ & $2,4,7$ & 65 & 16 & $8-9$ & $\begin{array}{l}\text { Late } \\
\text { flowering }\end{array}$ \\
\hline $\begin{array}{l}\text { June } 10 \ldots \ldots \ldots \ldots \\
\text { 3rd stage }\end{array}$ & $2,4,8$ & 70 & 19 & $11-12$ & Set \\
\hline $\begin{array}{l}\text { June } 18 \ldots \ldots \ldots \\
\quad \text { 4th stage }\end{array}$ & $3,5,8$ & 80 & 23 & 14 & $\begin{array}{l}\text { Berries } \\
\text { about } 8 \mathrm{~mm} \\
\text { in diameter }\end{array}$ \\
\hline $\begin{array}{l}\text { July } 14 \ldots \ldots \ldots \ldots \\
\quad 5 \text { th stage }\end{array}$ & $3,5,7$ & 80 & 25 & 18 & $\begin{array}{l}\text { Onset of } \\
\text { rapid sugar } \\
\text { increase }\end{array}$ \\
\hline
\end{tabular}

week before flowering, and July 14, when the sugar content of the fruit was increasing rapidly (table 3). Six hours after treatment the shoots were harvested. The direction of translocation of the photosynthate from selected leaves on the shoot was followed and related to the power of the sinks.

Nodal instead of internodal sections were mounted from one of the replicate shoots on May 18 (see fig. 20). Axillary buds were not sectioned or mounted on June 10 and 18, and July 14. Treated leaves were not mounted, but their position is designated on the radioautographs by the symbol TL.

First developmental stage. The first series of shoots was treated on May 18, a week before the beginning of flowering (table 3). In all, leaves on six replicate shoots were treated.

Translocation from leaf number 2 (basal to the cluster) was mainly acropetal into the shoot tip (fig. 18). Activity in the lowermost internode of the shoot was intense, but only faint activity could be detected in the spur. It is unlikely that much photosynthate was translocated out of the shoot. Some activity appeared in the peduncle, but none was detected in the cluster branches.

Translocation from the leaf opposite the cluster was both acropetal and basal as well as across the stem and into the cluster (fig. 19). Photosynthate moved apically into the axillary buds and shoots on both sides of the shoot and into the shoot tip. The downward movement was into the axillary buds on the same side of the stem as the treated leaf and out of the shoot into the 


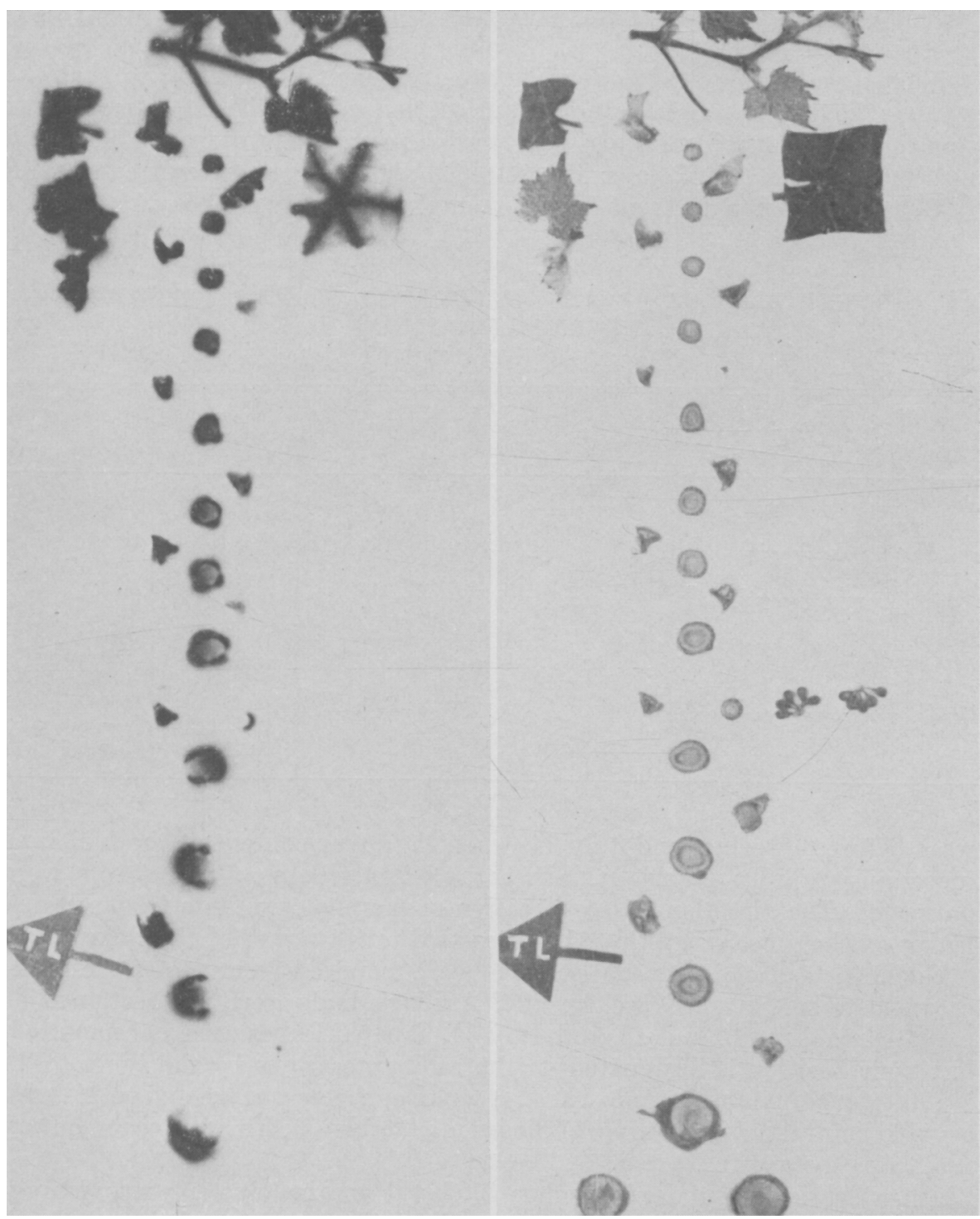

Fig. 18. Leaf number 2 located below the inflorescence of a partially defoliated shoot treated May 18, 1961, 7 days before flowering. Shoot harvested 6 hours after treatment. Left, radioautograph; right, mounted specimens. TL. Position of treated leaf. The two sections at the bottom are cross sections of the spur; the one on the right is basal to the shoot. Note that movement of photosynthate is mainly acropetal and that there is activity in the peduncle.

1-year-old wood (spur) of the parent vine. On this shoot no photosynthate was translocated to the oldest leaf on the shoot tip. Probably this leaf was mature enough to be exporting photosynthate. The activity in the inflorescence was unevenly distributed among the branchlets. 


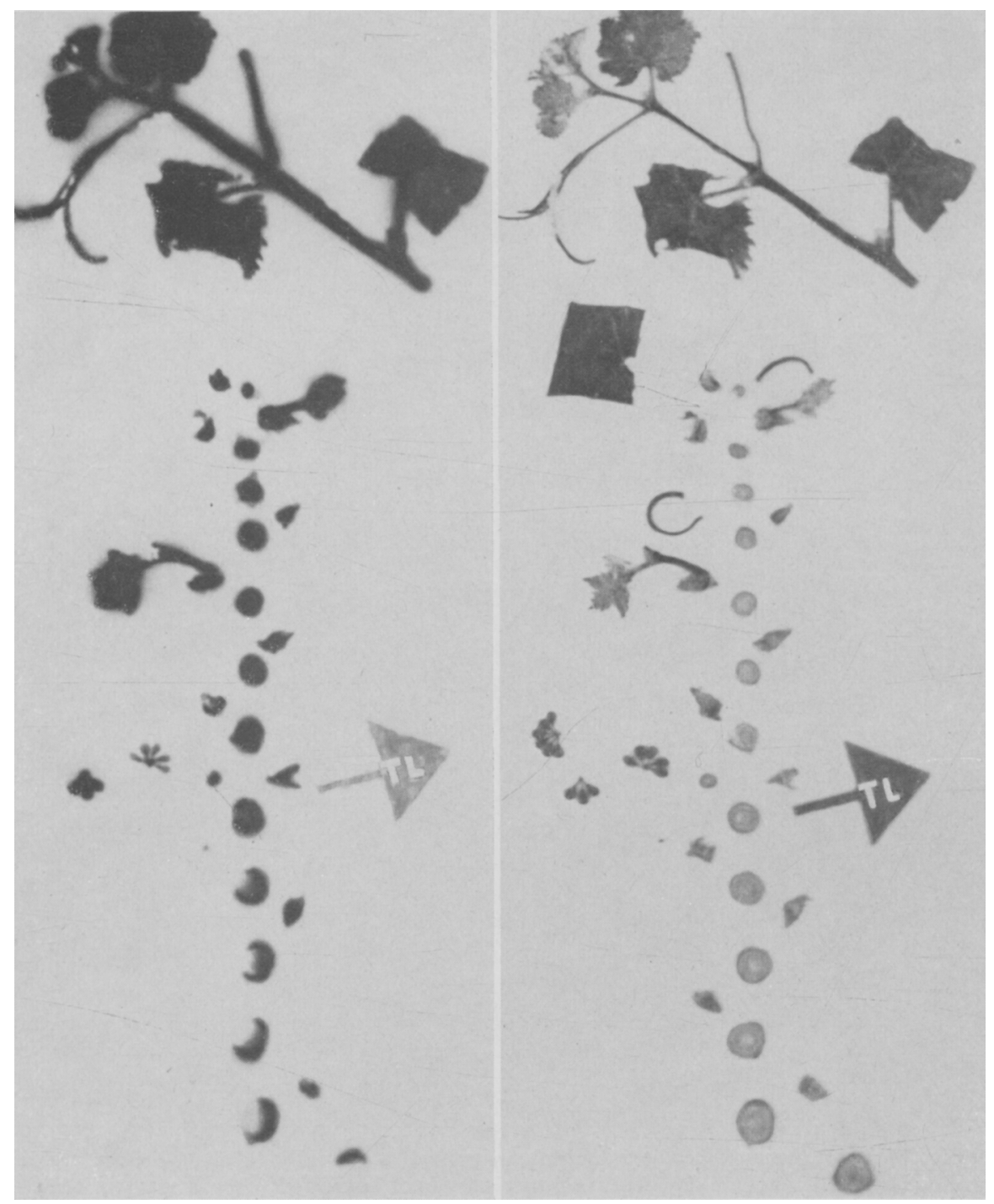

Fig. 19. Leaf number 5, opposite the inflorescence of a partially defoliated shoot treated on May 18, 1961, about 7 days before flowering. Shoot harvested 6 hours after treatment. Left, radioautograph; right, mounted specimens. TL. Position of treated leaf. The lower right section is a cross section of the spur. Note basipetal movement of photosynthate out of the shoot into the wood of the parent vine, and intense activity in most plant parts.

In a third shoot, leaf number 8, located three nodes apical to the cluster, was treated with $\mathrm{C}^{14} \mathrm{O}_{2}$. Translocation of photosynthate from the treated leaves was chiefly acropetal and into the shoot tip (fig. 20). Only very faint activity occurred in the inflorescence.

Second developmental stage. A second series of defoliated shoots was treated on May 30 when capfall had ended (table 3). (Capfall refers to the 


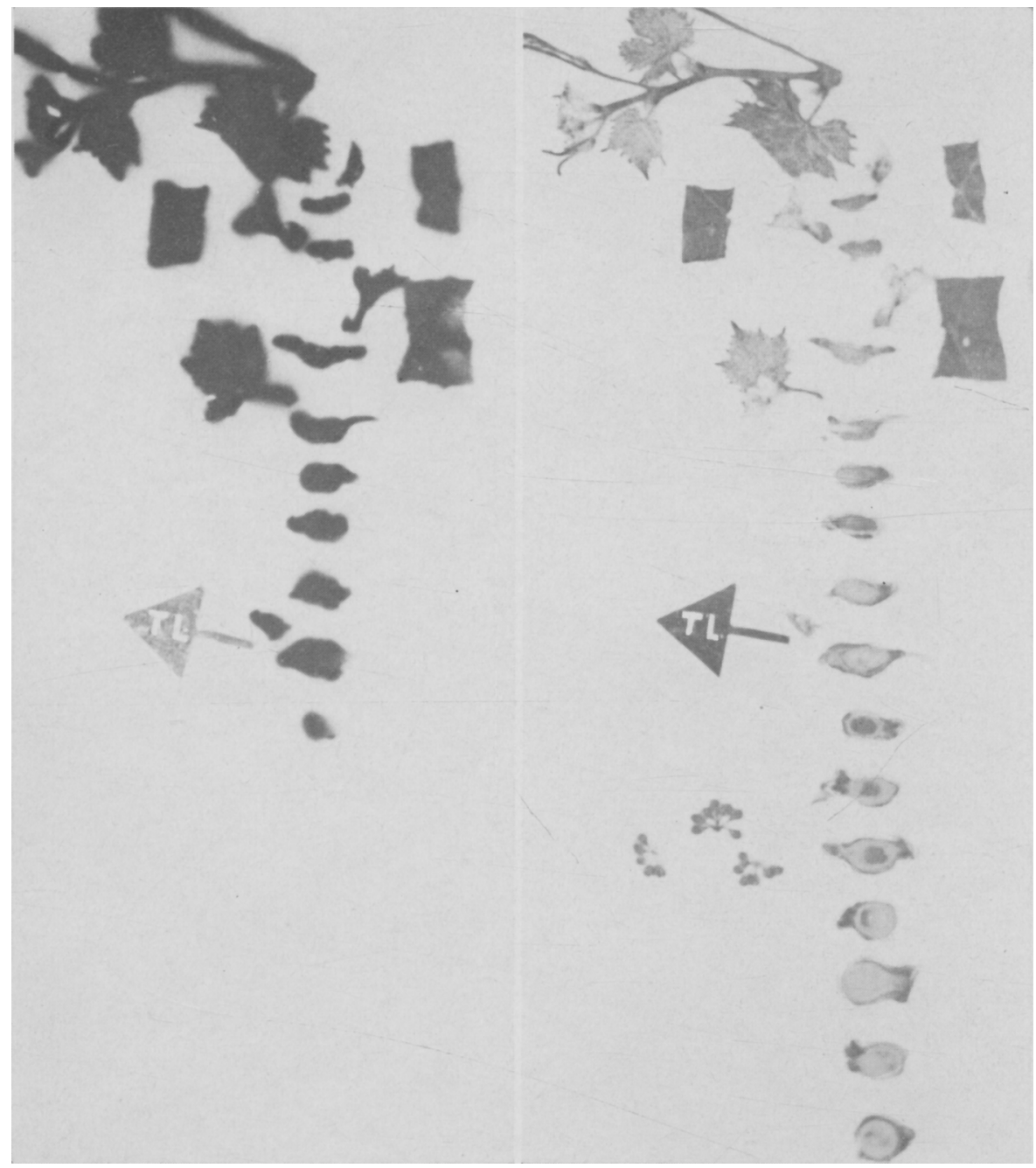

Fig. 20. Leaf, three nodes ahove the inflorescence of a partially defoliated shoot, treated on May 18, 1961, ahout 7 days hefore flowering. Shoot harvested 6 hours after treatment. Nodal sections of stem mounted in this figure. Left, radioautograph ; right, mounted specimens. TL. Position of the treated leaf. Note that movement of photosynthate is mainly acropetal and that activity in the shoot tip is intense.

separation of the calyptra from the rest of the flower during the bloom period.) Translocation of photosynthate from treated leaves below the cluster was both acropetal and basipetal in two replicate shoots. The intense activity in the lowermost stem sections suggests that much photosynthate was exported out of the shoot.

On two shoots, the leaf opposite the inflorescence was treated. In both shoots the photosynthate was translocated across the stem into the inflores- 


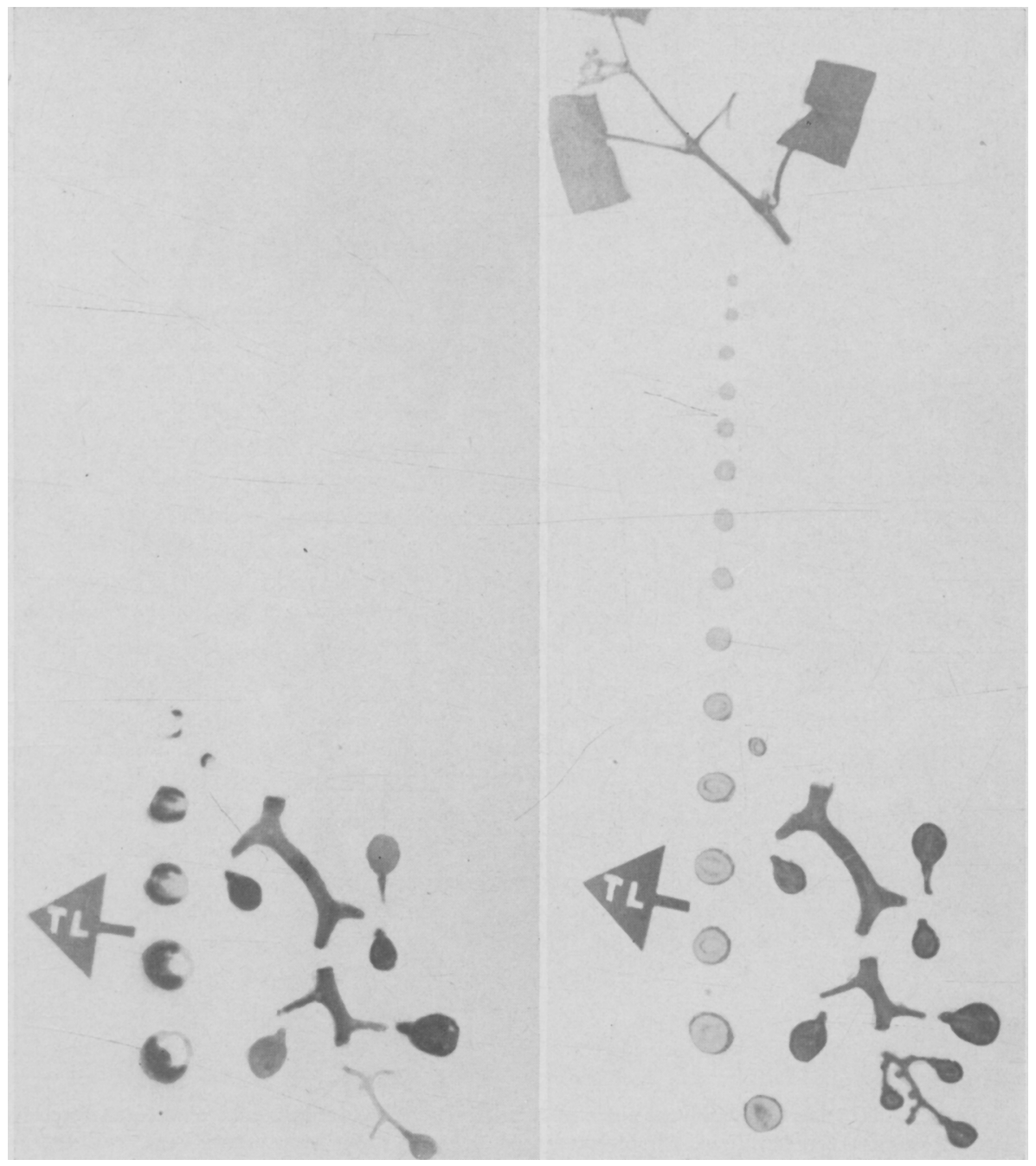

Fig. 21. Leaf below cluster on a partially defoliated shoot treated on June 10, 1961, about 4 days after fruit set. Shoot harvested 6 hours after treatment. Left, radioautograph ; right, mounted specimens. TL. Position of treated leaf. Lower right section is cross section of the spur. Note that movement of photosynthate was mainly into the cluster and that there was none to the shoot tip. There was no movement of photosynthate out of the shoot.

cence and also both upwards and downwards from the treated leaf. More acropetal movement occurred in the second shoot. Possibly the second shoot tip was a more powerful sink because it was growing more rapidly.

In two other shoots, on which the treated leaf was three nodes apical to the inflorescence, the photosynthate was translocated acropetally into the shoot tip and basipetally into the inflorescence. No activity was detected farther than two internodes below the inflorescence. The tip of the first shoot 


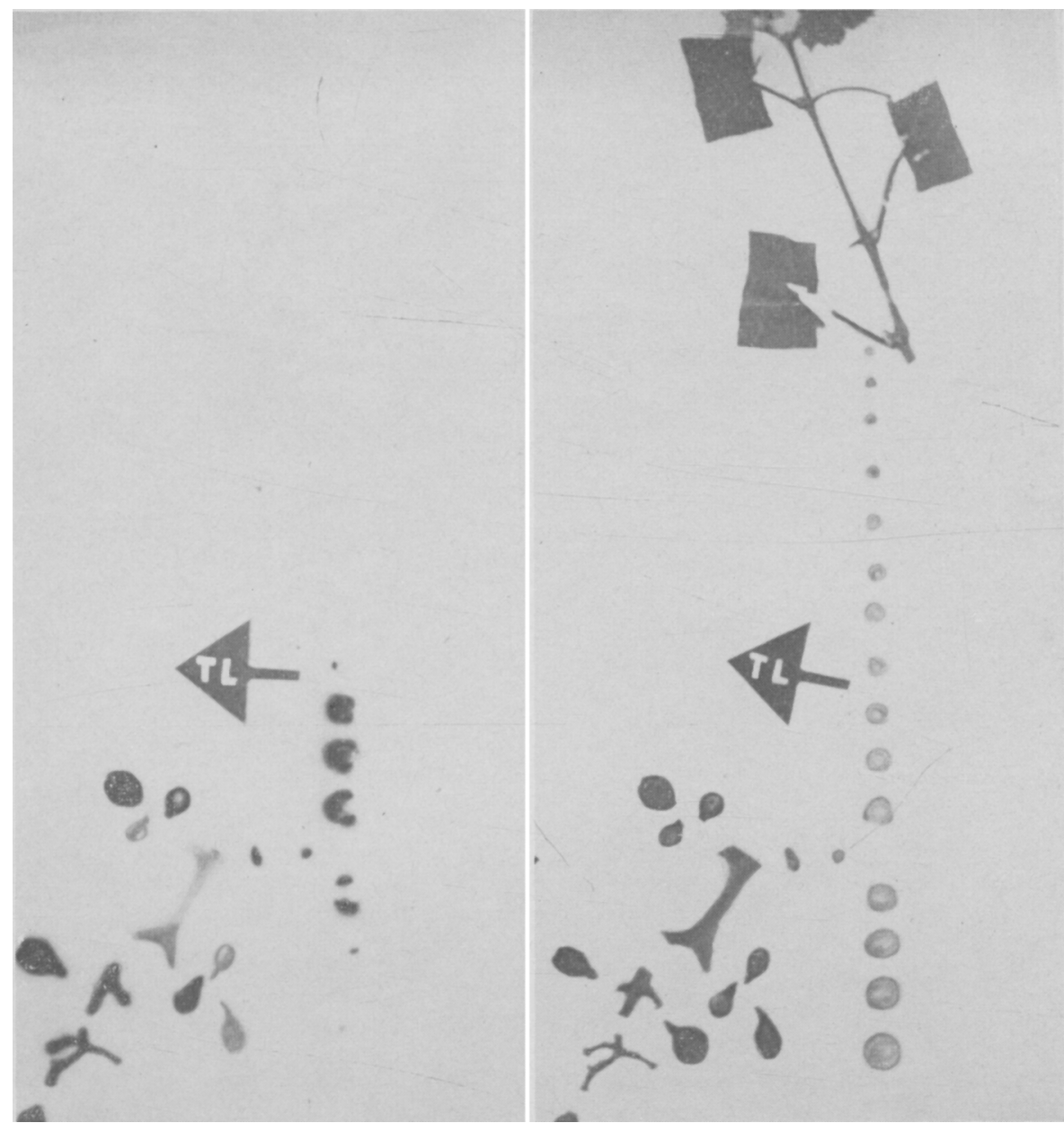

Fig. 22. Leaf ahove the inflorescence of a partially defoliated shoot treated on June 10, about 4 days after fruit set. Shoot harvested 6 hours after treatment. Left, radioautograph; right, mounted specimens. TL. Position of treated leaf. Note that activity moved into the cluster but that none moved into the shoot tip or the parent vine.

had less radiocarbon than the tip of the second. The tip of the second shoot was large and apparently growing rapidly, creating a strong sink. It evidently diverted or weakened the stream of elaborated food materials entering the cluster. This hypothesis is supported by the more intense activity in the inflorescence of the first than the second shoot.

Third developmental stage. A third series of defoliated shoots was treated on June 10 after the normal shatter of berries following flowering was completed. Export of $\mathrm{C}^{14}$ from a leaf two nodes below the cluster was predominantly into the cluster on the opposite side of the shoot (fig. 21). Some activity was detected in two internodes above the cluster, but it became increasingly faint with distance from the cluster. The second internode below 
the treated leaf showed activity, but none was detected in the spur. Activity in the apical portion of the cluster was less than in the basal portion.

Export of photosynthate from a leaf opposite the cluster was mainly across the stem and into the cluster. Translocation from a treated leaf arising three nodes above the cluster on the same side was basipetal and mainly into the cluster (fig. 22). Vertical movement of $\mathrm{C}^{14}$ was confined to the stem segment between the internode above the treated leaf and the second internode below the cluster. In the internode below the cluster, activity occurred in two distinct bands, but above the cluster it was in one continuous band.

Fourth developmental stage. This series of defoliated shoots was treated on June 18, when growth in length had almost ceased (table 3 ).

Translocation of $\mathrm{C}^{14}$ from the treated leaf below the cluster, leaf number 3 , was acropetal into the cluster and beyond it for four or five internodes. The region of highest activity in the fruit was the seed, although the vascular strands also showed much activity. On the shoot where the leaf opposite the cluster was treated, the activity was translocated across the stem into the cluster and upward for eight internodes. The activity in the berries varied from none to very intense. When the leaf four nodes above the cluster was treated, translocation was acropetal into the shoot tip. In all shoots photosynthate moved only one or two internodes below the treated leaf.

Fifth developmental stage. The fifth and final series of defoliated shoots was treated on July 14 (table 3 ). The degrees Balling of the juice was 6 . In this series, only stems and pedicels of clusters were mounted.

When the leaf below the cluster was treated, the activity was translocated up into the cluster and from one to five internodes apical to it. Photosynthate moved basipetally only as far as the second internode below the treated leaf.

Translocation from the treated leaf opposite the cluster was chiefly across the stem into the cluster and upwards for three or four internodes. Activity in the cluster appeared to be fairly well distributed.

When the leaf arising three nodes above the cluster was treated, movement of photosynthate was acropetal for four internodes and also basipetal into the cluster. The activity in several internodes above the cluster was intense but it was faint in the internode below it. In this shoot the cluster and stem tissues in the vicinity of the cluster were the main sinks.

These data show that the cluster is a powerful sink when sugar begins increasing rapidly in the berry.

\section{DISCUSSION}

Since interpretation of many of the experimental results is rather complex, the discussion has been divided into several main sections dealing with single aspects of translocation.

Direction of translocation in the shoot. A voung leaf developing at the shoot tip is at first parasitic on the rest of the vine, and imports elaborated food materials. Leonard and Weaver (1961), using radioactive 2,4-D and Amitrole, found that leaves were importing when they were less than one third of their final size. The leaf displays a typical sigmoid growth curve and, when it is about half its full size, begins exporting carbohydrate materials (fig. 14). 
This export of photosynthetic products was at first acropetal into the shoot tip and was largely unidirectional (figs. 2, 7). One would expect the movement to be largely apical because of the close proximity of the powerful sink provided by the rapidly growing shoot tip. In a newly developing shoot in the spring, the oldest leaf did not export photosynthate until the shoot was 2 to 3 weeks old. At this time the shoot was about $15 \mathrm{~cm}$ long and had about five leaves. When leaf number 1 started exporting carbohydrate, on about April 25, it was still growing (table 1). Leaves number 1 and 2 probably reached the exporting stage at about the same time early in May. At Davis, shoots grew about $2 \mathrm{~cm}$ per day in the spring so that the age of adjacent leaves on the stem differed by only about 1 or 2 days.

The strictly acropetal movement from the newly exporting leaf did not last for more than 1 or 2 days. With the development of one additional exporting leaf, the direction of translocation from the first leaf became bidirectional. A portion of the photosynthate then started to move basipetally out of the shoot and into the spur of the parent vine (fig. 16). This change in the direction of the translocation from each individual leaf was repeated as the leaf reached and entered the exporting stage of growth. The change in the distribution of photosynthate during ontogeny of the shoot was in accordance with the concepts described by Swanson (1959).

The role of the parent vine as a sink at such an early stage of growth of the shoot is of special interest. It has been believed that young, rapidly growing shoots are completely parasitic on the parent vine and hence only import food materials. This theory has been suggested by data obtained from experiments in which changes of carbohydrate materials were followed in various parts of the vine at various stages of growth (Winkler and Williams, 1945; Stoev et al., 1960). The movement of $\mathrm{C}^{14}$-labeled 2,4-D and Amitrole was followed in Tokay shoots, but no downward movement of the label from leaves apical to the cluster was detected until the shoots were 3 or 4 feet long (Leonard and Weaver, 1961). Some movement of the label down the stem into the cluster was then detected, but no determinations were made to see whether it moved out of the shoot.

Bidirectional translocation from the newly exporting leaf lasted for only a short time, perhaps 2 or 3 davs, before the direction of translocation was completely reversed and became strictly basipetal. The leaf's former function of supplying the growing shoot tip with elaborated food materials was taken over by the vounger leaves closer to the shoot tip. The rapid rate of change in direction that took place was indicated by one shoot in which strictly basipetal translocation from leaf number 7 occurred only 4 weeks after the first leaf started exporting. Thus within 4 weeks the direction of translocation of 6 or 7 leaves had become completely reversed. A similar reversal in the direction of translocation of 2,4-D and Amitrole was also observed in the Tokay shoot (Leonard and Weaver, 1961).

Once the translocation of photosynthate from leaves apical to the cluster became basipetal only, the movement continued in that manner. The direction of translocation from leaves below the cluster became bidirectional again after the shatter of berries following flowering and continued this way throughout ripening of the fruit (fig. 11). Acropetal movement from these 

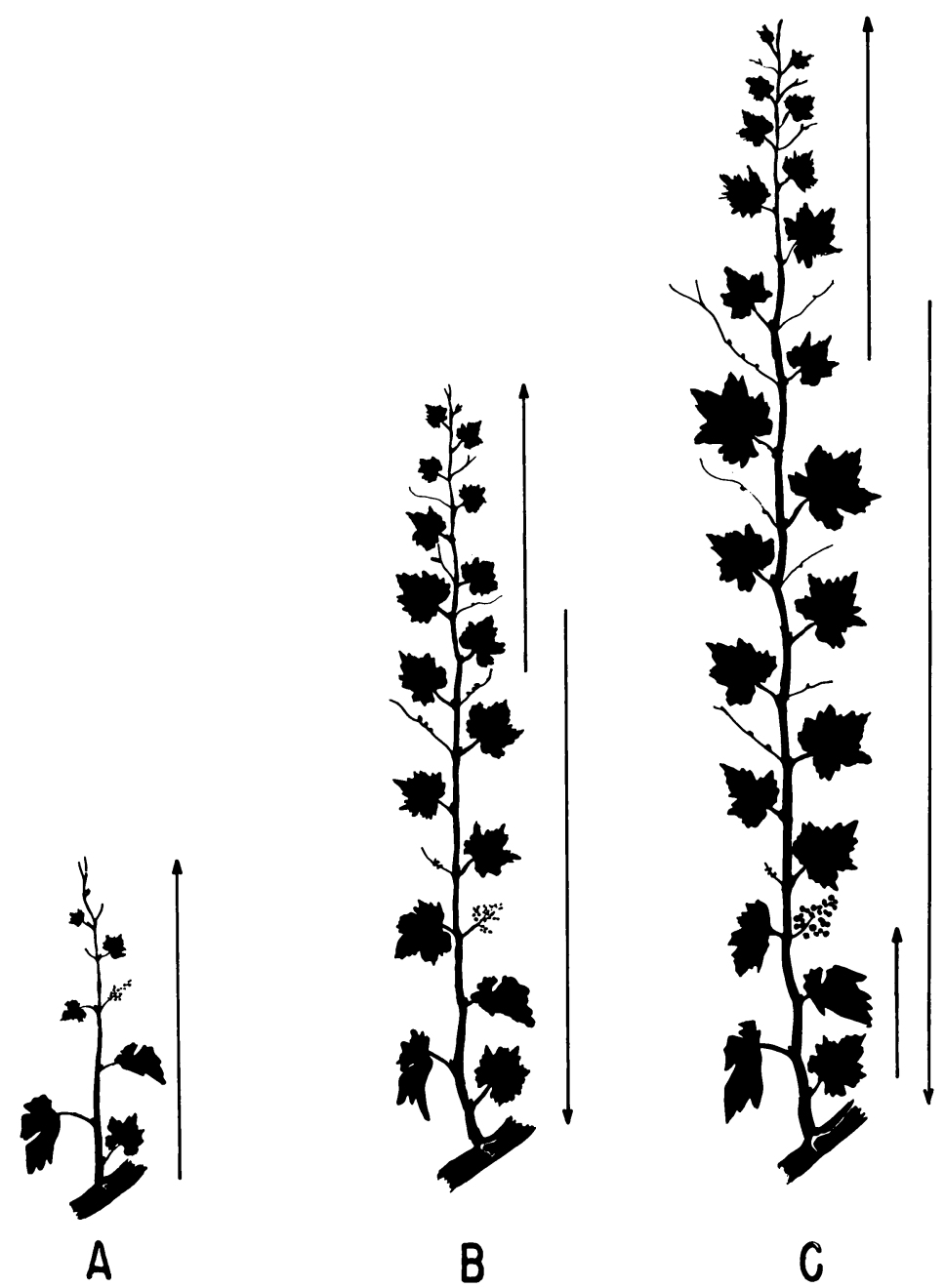

Fig. 23. Diagram of a rapidly growing grape shoot at three different developmental stages showing main direction of movement of photosynthate. A. Movement in a very young shoot or shoot tip is apical. B. In the prebloom or bloom stage export is bidirectional from two or three leaves below the shoot tip. Below this region movement is basal. C. After the set of fruit, photosynthate also moves apically into the cluster from leaves below the cluster. After the rate of shoot growth decreases several weeks following set stage, photosynthate moves basally from the tip.

leaves, except with defoliated shoots, never extended above the cluster (figs. $5,11)$. This would be expected because the developing fruit is a powerful sink, and since the growth of the shoot tip slows down by the middle of June, the tip becomes only a weak sink.

The movement of photosynthate out of the young shoots does not imply or prove that there is no movement of food materials from the parent vine 
into the shoots. In fact, young shoots have always been thought of as importers of food materials. It has been demonstrated in bean plants that simultaneous bidirectional movement can occur in the same phloem bundle (Biddulph and Cory, 1960). Materials could be moving in one direction in one sieve tube and in the opposite direction in another. Experiments are needed in which roots or other parts of the parent vine are treated with labeled materials so that their movement upward can be followed.

The general direction of movement of photosynthate in young shoots of three stages of development is shown in figure 23. Considering a rapidly growing shoot as a whole, one can generalize that the translocation in the terminal portion is acropetal only. Movement of photosynthate from the two or three youngest exporting leaves is almost exclusively to the shoot tip (figs. 2, 7). Below this there are several leaves which export to both tip and parent vine. Basal to this is a region where translocation is basipetal only. $\Lambda$ fter set, movement is bidirectional in the region between the eluster and parent vine. When the rate of shoot elongation sharply decreases several weeks after set, much photosynthate moves basipetally from the apex. This general pattern is similar to that found in other plants such as sova bean (Aronoff, 1955), pea (Linck, 1955) and morning glory (Crafts, 1956). However, no such studies on mature woody plants are known to the writers.

The direction of translocation of photosvnthate from a leaf of a young grape shoot at prebloom stage is determined by the sinks represented by the shoot tip or the parent vine. The influence of shoot tip, flowers and fruit, roots and other possible sinks on the morement of translocate has been pointed out by a number of workers. The controlling effect of meristematic tissues and storage organs on the direction of translocation has been well established (Crafts, 1961). A significant observation on translocation in young grape shoots is that the period of dependence on the parent vine may be very short. Also of interest is the finding that the flower cluster has only a small influence on movement of photosynthate.

Linearity of transport. Translocation from a given leaf is often linear, that is, it is restricted to the vertical transport systems more or less in line with the leaf or branch supplying the translocate (Swanson, 1959). In the Muscat shoot, linearity of transport was usually observed, but under certain circumstances this was modified by leaves or by the fruit cluster. Leonard and Weaver (1961) found that lateral transport of 2,4-D and of Amitrole in the Tokay shoot occurred only in the apical portion. They stated that this uniform lateral distribution of photosynthate was a result of anastomoses of the primary phloem at the nodes. The present investigation in the Muscat shoot shows a similar uniform distribution of photosynthate in the apical region bearing very young leaves.

The effect of the fruit cluster in diverting the vertical translocation pattern is clearly illustrated in the shoots shown in figures 12 and 13. The polarizing power of the cluster on translocation was sufficient to divert the photosvnthate moving down the shoot from its normally vertical path. In some shoots the lateral diversion of photosvnthate was demonstrated by the presence of activity in axillary buds (figs. 10,12). Here the cluster diverted photosynthate laterally from one side of the stem to the other. In nearly all 
cases the movement of photosynthate from one side of the stem to the other occurred within the vertical distance of one internode.

The rapid movement of photosynthate from one side of the stem to the other is probably made possible by the development, in secondary growth, of vascular elements which traverse the wide parenchyma rays separating the vascular strands (Esau, 1948).

Frequently where the export of photosynthate from a treated leaf was mainly acropetal and into the shoot tip, there was also some basipetal movement. This basipetal movement was usually restricted to one or two internodes below the treated leaf (figs. 7, 20). Usually when the downward movement terminated in the second internode below the treated leaf, there was less activity in it than in the first below the treated leaf. Arbaumont (1881) found that leaf traces in Vitis traversed not less than two or three internodes and that the junction with other bundles occurred at the node. The evidence obtained in the current studies on translocation in the Muscat shoot indicates that leaf traces can be shorter than two or three internodes, that the length of the leaf traces is variable, and that the junction of the leaf traces is at a node.

Translocation to the parent vine. The parent vine is used to designate that part of the vine exclusive of the succulent shoot growth. In this paper the whole parent vine is referred to as a sink, although the chief sink may be the roots or certain other portions of the parent vine. The roots are the main storage organs of the vine, starch being the chief storage form of available carbohydrate (Winkler and Williams, 1945). During early spring growth, the parent vine, especially the roots, may be viewed as a source of food for growth of the whole vine including the shoots. After these foods have been depleted by about midsummer, the supply is built up again. During this period of growth the parent vine can be considered to be a sink for the foods manufactured by the leaves.

The depletion and build-up of available carbohydrate materials (sugars and starch) in the various tissues of the vine were followed in 4-year-old Carignane vines for one annual cycle by Winkler and Williams (1945). They found that, in the aerial parts, the starch content decreased until midJune, but that, in the roots, the depletion continued for 5 or 6 weeks longer. These authors considered that the reserves in the roots may have been used for active shoot development in the spring as well as for growth of the parent vine.

In the Muscat vine, photosynthate moved out of the shoot at a very early stage of shoot development. Export began before the most rapid stage of shoot growth had commenced. In this work, the movement of radioactivity was not followed basally to the spur, but it would be desirable to trace the photosynthate throughout the parent vine. The extent to which shoot growth, flower development, and fruit set are affected by the parent vine acting as a source or sink for food materials is not definitely known. The parent vine is probably a stronger sink following a year of heavy overcropping, since food reserves are quite depleted. It is well known that overcropping is associated with weak shoot growth, straggly clusters, and fruit low in sugar.

It is possible that under certain circumstances the root reserves cannot 
be mobilized rapidly enough to satisfy the needs of root growth. The roots and the shoot tip would then be competing for the food produced by the first leaves to start exporting.

Translocation to the shoot tip. In its early development, the whole shoot can be considered to be the shoot tip and the materials necessary for its growth are translocated to it from the parent vine. In these experiments, after the young shoot developed several exporting leaves, the photosynthate from the two or three youngest exporting leaves moved almost exclusively to the shoot tip (figs. 2, 7), while export from the next older one or two leaves moved to both the shoot tip and the parent vine (fig. 19). The shoot tip appeared to receive photosvnthate from four or five leaves.

The number of leaves which translocate to the shoot tip varies according to the growth rate of the shoot, the size and photosynthetic capacity of the exporting leaves, the developmental stage of the vine, and the demands of the parent vine. All these factors may be influenced by either environment or genetic combinations. The results with Muscat are in general agreement with those of Coombe (1959), who studied fruit set on girdled shoots defoliated to varying degrees with several seeded varieties. He found the shoot tip used the food materials and other substances from the equivalent of about one to six mature leaves as measured by the depressant effect of the shoot tip on set of berries. $\Lambda$ t bloom there are usually about ten to twelve exporting leaves and therefore more than one half of the photosynthetic product of the shoot goes to the parent vine.

Translocation to the inflorescence and fruit. When photosynthate moved into the shoot tip from the first leaf to start exporting on a young shoot, the flower cluster had limited power to compete with the young, expanding leaves for food materials. Only when the cluster was on the same side of the shoot as the treated leaf, did activity move into the cluster in large amounts at this early stage. Thus young clusters had only limited power to change the basically linear transport in the young shoot (fig. 16). This is probably related to the long parallel course of the vascular bundles in the primary phloem of Vitis (Arbaumont, 1881).

Clusters were rather strong sinks while they were rapidly increasing in size. About 10 to 14 days before bloom, the rate of cluster growth decreased. This corresponded with the decreasing power of the cluster as a sink. Flower clusters continued to be weak sinks until berry set began. For example, on May 12, 1961, ten days before bloom, there was no movement of photosynthate into the cluster from the leaf above it; translocation from this leaf was strictly acropetal. In another shoot the treated leaf was above the cluster but on the opposite side of the stem. Although the activity was translocated basipetally past the cluster, no activity entered the cluster. It was not known whether the cluster at this prebloom stage had only a small requirement for assimilates, or whether it could not compete successfully with the shoot tip or parent vine for them.

At the late prebloom stage, the overall growth of the cluster was small compared to that of the shoot tip and the parent vine. The pruning experiments of Winkler (1929) provide evidence that the carbohydrate nutrition of the inflorescence in the prebloom stage can markedly affect flower and 
cluster development and fruit set. He attributed the better flower and cluster development and fruit set on the less severely pruned vines to the earlier and greater development of leaf area.

The growth response of the cluster to applied gibberellin is maximal in the period of rapid cluster growth from early April to early May, and only slight elongation of Zinfandel clusters occurred when they were treated with gibberellin after May 14 (Weaver and McCune, 1959a).

The relative power of the flower cluster as a sink compared to the shoot tip and the parent vine did not change at full bloom on May 26, 1961. Very little photosynthate entered the cluster from leaves either above it or below it, although some did enter from exporting leaves above and on the same side of the shoot as the cluster. At no stage from prebloom through flowering, did the flower cluster appear to influence the longitudinal direction of movement of the translocate in the stem. This is in agreement with the results of Leonard and Weaver (1961), who found that the shoot tip is a much more powerful sink than the cluster in the Tokay shoot at the prebloom stage. In the Muscat shoot the parent vine is also a more powerful sink than the cluster. Leonard and Weaver (1961) found downward movement of 2,4-D into the cluster from a leaf above it. The sink that caused this downward movement was probably the parent vine rather than the cluster.

The shoot tip was the dominating sink in the experiments in which the shoots were partially defoliated at a prebloom stage (fig. 18). In only one of the six shoots treated at this stage of growth was there movement of photosynthate out of the shoot. Little or no photosynthate was translocated into the cluster from leaves above it (fig. 20), but photosynthate did move into the cluster from treated leaves opposite or below it.

The clusters on the defoliated shoots at bloom appeared to be more powerful sinks than they were at the prebloom stage. Radiocarbon moved into the cluster from leaves above, opposite, and below it. No photosynthate moved into the shoot tip when the leaf below the cluster was treated. Thus the cluster appeared to be a strong sink several days after full bloom.

The clusters on the defoliated shoots were also stronger sinks than corresponding clusters on normal shoots. The experiments on the defoliated shoots were conducted 3 days later than those on the normal shoots. This 3-day period may have been long enough for the cluster to develop into an appreciably stronger sink as a result of inception of fruit set. Coombe (1960) found that cell division in the pericarp of the developing grape berry reached a maximum rate 5 to 10 days after full bloom ( 70 per cent capfall). It may be that the increasing power of the cluster as a sink at this time was due to pericarpal growth. Another possible explanation of the difference in the power of the clusters as sinks on normal and defoliated shoots is that in the 2-day interval between defoliation and treatment, the translocation pattern in the vine may have altered. It may be that the parent vine was changed from a sink to a source by the defoliation of the shoot. Linck (1955) has shown that rapid changes in the translocation patterns can occur. Such a reversal of role could have occurred in the shoots from which no activity was exported. It is unlikely to have occurred in shoots in which strong downward movement to the lowermost internode section took place. 
The results on normal shoots support the contention of Coombe (1959) based mainly on the effects of girdling, topping, defoliation, and feeding experiments on fruit set, that the cluster is a very weak sink in the period after full bloom.

The cluster becomes the dominating sink after the set of berries, which is completed about 10 days after full bloom. This powerful sink is in great contrast to the weak sinks of the prebloom and flowering cluster. On defoliated shoots, photosynthate moved into the cluster from leaves below, opposite, and above the cluster, and in no instance did translocation to the shoot tip or the parent vine occur (figs. 21, 22).

It is generally believed that flowers and developing fruit are strong sinks although there is some evidence to the contrary (Shiroya et al., 1961). However, the data in this paper show that grape flower clusters are weak sinks. Coombe (1959) also concluded that grape clusters going into the period of setting are weak sinks. He pointed out that although grape ovaries and berries are in a static condition during the setting period, it is during this period that such practices as topping, pinching, and girdling, can improve set on varieties subject to coulure (excessive berry shatter). Also, in maize, Loomis (1945) found that the ear had no polarizing power on translocation for several days prior to pollination. The setting period can be viewed as the final stage of a period in which the flower cluster has small competitive power as a sink. During this period, the direction of the translocation stream is determined by the shoot tip and the parent vine and the cluster has limited ability to withdraw metabolites from the passing stream. After berry set, the cluster becomes a more powerful sink and at the same time the shoot tip becomes a less powerful sink as rate of shoot growth decreases.

These experiments can help explain the variable response of grape clusters to growth regulators applied to foliage and/or clusters as obtained by Weaver and McCune $(1957 ; 1959 a ; 1959 c)$. Differences in response can usually be correlated with variations in the power of the cluster as a sink. Bagging experiments in which foliage and/or clusters were treated with 4-chlorophenoxyacetic acid (4-CPA) or gibberellin showed that much gibberellin entered the cluster at an early prebloom stage through the leaves. At bloom, practically no growth regulator entered the clusters of Black Corinth through the foliage. When Thompson Seedless was treated with plant growth regulators after set, much 4-CPA and considerable gibberellin reached the cluster through the leaves. The absence of any great polarizing effect on translocation by the cluster prior to set also explains why the best results are obtained from cluster rather than foliage applications of growth regulators in the bloom and preset stage.

The practices which improve set, either in the prebloom period or the setting period, are ones which appear to modify or eliminate either of the two sinks (shoot tip or parent vine) which determine the direction of the movement of photosynthate. For example, topping removes the shoot tip, and girdling isolates the shoot temporarily from the parent vine.

The nutrition of the cluster during this period may depend on the degree of "loading" of the phloem transport system (Barrier and Loomis, 1957). The concentration of sucrose in the sieve tubes is high when the rate of 
supply of sucrose is as great or greater than its rate of use. Topping or girdling reduces the rate of use and a relatively high concentration of sucrose is maintained in the sieve tubes. Winkler (1931) showed that lightly pruned vines produced more foliage than heavily pruned vines especially early in the season. It is probable that the greater amount of foliage is associated with a high degree of vein loading.

Translocation to minor sinks. In addition to the shoot tip, parent vine, and the cluster, which are the major sinks, there are several minor sinks. These are the axillary buds, tips of lateral shoots, tendrils, cambium, phloem, xylem, parenchyma, and pith. These minor sinks had no apparent influence on the longitudinal direction of translocation.

The chief source of photosynthate for the axillary buds appeared to be the leaf which subtended them. The activity in the bud subtended by the treated leaf was generally much higher than that in any other axillary bud. Normally, photosynthate moved into those axillary buds on the same side of the shoot as the treated leaf. Unless a fruit cluster or young leaf modified the basic linearity of transport, the activity occurring in buds on the side of the stem opposite to the treated leaf was very small.

Photosynthate moved to axillary shoots from the parent shoot only until one or two of their leaves had matured; after that the movement from the parent shoot ceased. Young tendrils were also active sinks, but had little or no influence on the direction of translocation. Tendrils arise at certain nodes apical to the clusters. Since adjacent leaves are much more numerous and larger than tendrils, the former are much more powerful sinks.

Considerable activity generally appeared in the pith of the younger portions of the shoot, but there was much less in the pith of the older sections (fig. 6). This can be explained by the decreased metabolic activity of pith cells in the older parts of the shoot. Also in the older parts, the secondary xylem was thick and hence the photosynthate had a longer distance to traverse radially to reach the pith. Frequently in the younger parts of the shoot where the activity in the pith was high, the pith was separated from the bark by a relatively narrow band of xylem which showed only slight activity. This may be indicative of a very rapid accumulation of labeled products in the pith cells. The occurrence of activity in the pith may also be explained by the movement of $\mathrm{C}^{14} \mathrm{O}_{2}$ from the treated leaf through the intercellular spaces in response to a pressure differential between leaf and roots (Crafts, 1961). The slight amount of photosynthate in the xylem of both young and old portions of shoots was probably located mainly in the ray parenchyma.

\section{SUMMARY}

The direction of translocation of $\mathrm{C}^{14}$ following the assimilation of $\mathrm{C}^{14} \mathrm{O}=$ by single leaves or shoot tips of the Muscat of Alexandria grapevine was determined by using radioautographic techniques. Experiments were designed to study the effects of leaf age and the position of the leaf related to shoot ontogeny on the direction of translocation from the leaf. In 1960, leaves near the apex, middle, or lower sections of the shoot were treated with $\mathrm{C}^{14} \mathrm{O}_{2}$ at four developmental stages. In 1961 the experiments were repeated at six stages of development between bud burst and blossoming. Other experiments were made on partially defoliated shoots. 
The grapevine leaf showed a typical sigmoid growth curve, the rapid growth phase occurring in the second and third weeks of leaf growth. The leaf attained its full size about 4 weeks after its growth started. Export of assimilate began when leaves were about half their final size.

The first assimilate exported by the leaf was to the shoot tip. When the leaf was separated from the oldest importing leaf on the shoot tip by two or three other exporting leaves, the assimilate from the leaf was translocated both to the shoot tip and to the parent vine. With further shoot growth the basipetal movement predominated until translocation from the leaf was completely reversed and was basipetal only. Translocation from leaves below the cluster was partially reversed again when fruit development started. Assimilate from these leaves was translocated both to the fruit cluster and to the parent vine. After the rate of shoot elongation decreased sharply, photosynthate moved from the shoot tip in a basipetal direction.

The young inflorescence had small power as a sink compared to the shoot tip and the parent vine, and was unable to influence the direction of translocation. From 10 to 14 days before bloom until fruit set, the cluster was a weak sink.

Axillary buds, tendrils, xylem, parenchyma, and pith were found normally to be weak sinks relative to the developing fruit cluster and unable to influence the longitudinal direction of translocation.

Axillary shoots behaved as young leaves until one or two of their leaves were mature. Then no assimilate moved into them from the main shoot.

Shoot tips and parent vines were more powerful sinks than the cluster during flower development but not during fruit set. Girdling and topping thus affect fruit set because they divert more assimilates into the cluster just prior to fruit set.

\section{LITERATURE CITED}

Arbatimont, J. D'

1881. Sur la disposition des faiseaux dans la tige, la feuille et les bourgeons de quelques plants de la famille des Ampélidées. Soc. Botan. de France Bull. 28:278-286. AronofF, S.

1955. Translocation from soybean leaves. II. Plant Physiol. $30: 184-185$.

BARRIER, G. E., and W. E. LOOMIS

1957. Absorption and translocation of 2,4-dichlorophenoxyacetic acid and $\mathrm{P}^{32}$ by leaves. Plant Physiol. 32 :225-231.

BIDDULPH, O.

1959. Translocation of inorganic solutes, p. 553-603. In F. C. Steward [ed.], Plant physiology: a treatise. Vol. II. Academic Press, New York, N.Y.

Bipdulph, O., and R. CORY

1960. Demonstration of two translocation mechanisms in studies of bidirectional movement. Plant Physiol. 35:689-695.

Coоmвe, B. G.

1959. Physiological aspects of fruit set and development in Vitis vinifera. Ph.D. Thesis, Univ. of California. 105 p. (Microfilm copies may be purchased from the University of California Library Photographic Service, Berkeley.)

1960. Relationship of growth and development to changes in sugars, auxins, and gibberellins in fruit of seeded and seedless varieties of Vitis vinifera. Plant Physiol. $35: 241-250$.

Crafts, A. S.

1956. Translocation of herbicides. II. Absorption and translocation of 2,4-D by wild morning-glory. Hilgardia $26: 335-365$.

1961. Translocation in plants. Holt, Rinehart and Winston, New York. 211 p. 
EsAu, K.

1948. Phloem structure in the grapevine and its seasonal changes. Hilgardia 18:217296.

Esau, K., H. B. Currier, and V. I. Cheadle

1957. Physiology of phloem. Ann. Rev. Plant Physiol. $8: 349-374$.

Kursanov, A. L.

1961. Translocation of organic substances in plants. Endeavour 20:19-25.

LEONARD, O. A., and R. J. WEAVER

1961. Absorption and translocation of 2,4-D and Amitrole in shoots of Tokay grapes. Hilgardia $31: 327-368$.

LiNCK, A. J.

1955. Studies on the distribution of phosphorus-32 in Pisum sativum, in relation to fruit development. Ph.D. Thesis, Ohio State University. (Microfilm copies may be purchased from University Microfilms, Ine., Ann Arbor, Michigan.)

Loomis, W. E.

1945. Translocation of carbohydrate in maize. Science $101: 398-400$.

Negrul', A. M., and L. T. Nikiforova

1958. Some interrelations between different organs of vines. [In Russian, French summary.] Izv. Timiryazev. seljsk. Akad., No. 1, p. 73-84.

Shiroya, M., G. R. Lister, C. D. Nelson, and G. KrotKov

1961. Translocation of $\mathrm{C}^{14}$ in tobacco at different stages of development following assimilation of $\mathrm{C}^{14} \mathrm{O}_{2}$ by a single leaf. Canad. J. Botan. 39:855-864.

Stoev, K. D., P. T. Mamarov, and I. B. Benchev

1960. Sugars and free amino acids during ripening and dormancy of the grape plant. Fiziol. Rastenii $7: 119-123$.

Swanson, C. A.

1959. Translocation of organic solutes, p. 481-551. In F. C. Steward [ed.], Plañt physiology, a treatise. Vol. II. Academic Press, New York, N.Y.

Swanson, C. A., and E. D. H. Eu Shishiny

1958. Translocation of sugars in the Concord grape. Plant Physiol. 33:33-37.

WeAver, R. J., and S. B. McCune

1957. Response of Thompson Seedless grapes to 4-chlorophenoxyacetic acid and benzothiazol-2-oxyacetic acid. Hilgardia 27 : 189-200.

1959a. Effect of gibberellin on seeded $\nabla$ itis vinifera and its translocation within the vine. Hilgardia 28 :625-645.

1959b. Girdling: its relation to carbohydrate nutrition and development of Thompson Seedless, Red Malaga and Ribier grapes. Hilgardia $28: 421-456$.

1959 c. Effect of gibberellin on seedless $\nabla$ itis vinifera. Hilgardia $29: 247-275$.

WINKLER, A. J.

1929. The effect of dormant pruning on the carbohydrate metabolism of Vitis vinifera. Hilgardia 4 :153-173.

1930. The relation of number of leaves to size and quality of table grapes. Am. Soc. Hort. Sci. Proc. $27: 158-160$.

1931. Pruning and thinning experiments with grapes. Univ. of California Agr. Expt. Sta. Bull. 519. 56 p.

1932. The lateral movement of elaborated foods in the grape vine. Am. Soc. Hort. Sci. Proc. 29 :335-338.

WinkLer, A. J., and E. M. SHEMSETTIN

1937. Fruit bud and flower formation in the Sultanina grape. Hilgardia 10:589-611.

Winkler, A. J., and W. O. Williams

1945. Starch and sugars of Vitis vinifera. Plant Physiol. 20:412-432.

Yamaguchi, S., and A. S. Crafts

1958. Autoradiographic method for studying absorption and translocation of herbicides using $\mathrm{C}^{14}$-labeled compounds. Hilgardia $28: 161-191$.

ZimMERMAN, M. H.

1960. Transport in the phloem. Ann. Rev. Plant Phvsiol. 11:167-190. 

The journal Hilgardia is published at irregular intervals, in volumes of about 600 pages. The number of issues per volume varies.

Subscriptions are not sold. The periodical is sent as published only to libraries, or to institutions in foreign countries having publications to offer in exchange.

You may obtain a single copy of any issue free, as long as the supply lasts; please request by volume and issue number from:

\author{
Agricultural Publications \\ 207 University Hall \\ 2200 University Avenue \\ Berkeley 4, California
}

The limit to nonresidents of California is 10 separate issues on a single order. A list of the issues still available will be sent on request.

In our publications it is sometimes convenient to use trade names of products or equipment rather than scientific identifications. In so doing it is unavoidable in some cases that similar products which are on the market under other trade names may not be cited. No endorsement of named products is intended nor is criticism implied of similar products which are not mentioned. 